\title{
THE
}

\section{The Operational GFDL Coupled Hurricane-Ocean Prediction System and a Summary of Its Performance}

\author{
Morris A. Bender \\ Isaac Ginis \\ University of Rhode Island, iginis@uri.edu \\ Robert Tuleya \\ Biju Thomas \\ University of Rhode Island \\ Timothy Marchok
}

Follow this and additional works at: https://digitalcommons.uri.edu/gsofacpubs

\section{Citation/Publisher Attribution}

Bender, M.A., I. Ginis, R. Tuleya, B. Thomas, and T. Marchok, 2007: The Operational GFDL Coupled Hurricane-Ocean Prediction System and a Summary of Its Performance. Mon. Wea. Rev., 135, 3965-3989. doi: 10.1175/2007MWR2032.1 Available at: https://doi.org/10.1175/2007MWR2032.1

This Article is brought to you for free and open access by the Graduate School of Oceanography at DigitalCommons@URI. It has been accepted for inclusion in Graduate School of Oceanography Faculty Publications by an authorized administrator of DigitalCommons@URI. For more information, please contact digitalcommons-group@uri.edu. 


\title{
The Operational GFDL Coupled Hurricane-Ocean Prediction System and a Summary of Its Performance
}

\author{
Morris A. BENDER \\ NOAA/GFDL, Princeton, New Jersey \\ ISAAC GINIS \\ Graduate School of Oceanography, University of Rhode Island, Narragansett, Rhode Island \\ Robert TUleyA \\ SAIC at NOAA/NWS/Environmental Modeling Center, Camp Springs, Maryland, and CCPO, Old Dominion University, \\ Norfolk, Virginia \\ BiJu THOMAS \\ Graduate School of Oceanography, University of Rhode Island, Narragansett, Rhode Island \\ TIMOTHY MARCHOK \\ NOAA/GFDL, Princeton, New Jersey
}

(Manuscript received 25 September 2006, in final form 13 March 2007)

\begin{abstract}
The past decade has been marked by significant advancements in numerical weather prediction of hurricanes, which have greatly contributed to the steady decline in forecast track error. Since its operational implementation by the U.S. National Weather Service (NWS) in 1995, the best-track model performer has been NOAA's regional hurricane model developed at the Geophysical Fluid Dynamics Laboratory (GFDL). The purpose of this paper is to summarize the major upgrades to the GFDL hurricane forecast system since 1998. These include coupling the atmospheric component with the Princeton Ocean Model, which became operational in 2001, major physics upgrades implemented in 2003 and 2006, and increases in both the vertical resolution in 2003 and the horizontal resolution in 2002 and 2005 . The paper will also report on the GFDL model performance for both track and intensity, focusing particularly on the 2003 through 2006 hurricane seasons. During this period, the GFDL track errors were the lowest of all the dynamical model guidance available to the NWS Tropical Prediction Center in both the Atlantic and eastern Pacific basins. It will also be shown that the GFDL model has exhibited a steady reduction in its intensity errors during the past $5 \mathrm{yr}$, and can now provide skillful intensity forecasts. Tests of 153 forecasts from the 2004 and 2005 Atlantic hurricane seasons and 75 forecasts from the 2005 eastern Pacific season have demonstrated a positive impact on both track and intensity prediction in the 2006 GFDL model upgrade, through introduction of a cloud microphysics package and an improved air-sea momentum flux parameterization. In addition, the large positive intensity bias in sheared environments observed in previous versions of the model is significantly reduced. This led to the significant improvement in the model's reliability and skill for forecasting intensity that occurred in 2006.
\end{abstract}

\section{Introduction}

The Geophysical Fluid Dynamics Laboratory (GFDL) hurricane prediction system became opera-

Corresponding author address: Morris A. Bender, NOAA/ GFDL, Forrestal Campus, P.O. Box 308, Princeton, NJ 08542. E-mail: morris.bender@noaa.gov tional in 1995 as the U.S. National Weather Service's (NWS's) official hurricane model. Since that time, it has provided forecast guidance to forecasters at the NWS Tropical Prediction Center (TPC) and has been the most reliable forecast model for track error during the past decade (Table 1). The GFDL system has made a significant contribution to the steady decline in the official track error since 1995 (Fig. 1). In addition, a ver-

DOI: 10.1175/2007MWR2032.1

(C) 2007 American Meteorological Society 
TABLE 1. Average track errors $(\mathrm{nm})$ for all forecasts run in the Atlantic between 1996 and 2005 for the GFDL, NCEP's GFS, Met Office, and U.S. Navy's NOGAPS models. Results are for the time-interpolated models. Because numerical weather prediction models are generally not available to the forecasters in time to make their forecasts, a simple technique exists to take the modelforecasted position and intensity, and adjust the forecast to apply to the current synoptic time and initial conditions. This adjustment is usually 6 or $12 \mathrm{~h}$, depending on the availability of the last model guidance. These adjusted versions are known for historical reasons as interpolated models, which are generally indicated by the letter "I" at the end of the name (e.g., GFDI for the GFDLinterpolated model). See Horsfall et al. (1997) for a more detailed explanation of the interpolation technique. Courtesy of J. Franklin, TPC.

\begin{tabular}{ccrrrr}
\hline \hline $\begin{array}{l}\text { Verifying } \\
\text { time (h) }\end{array}$ & $\begin{array}{c}\text { No. of } \\
\text { cases }\end{array}$ & GFDI & GFSI & UKMI & NGPI \\
\hline 00 & 2252 & 8.0 & 8.0 & 8.0 & 8.0 \\
12 & 2128 & 38.8 & 42.8 & 44.9 & 43.3 \\
24 & 1952 & 67.1 & 73.7 & 77.7 & 74.2 \\
36 & 1741 & 93.9 & 104.4 & 108.8 & 105.4 \\
48 & 1511 & 122.8 & 135.2 & 136.7 & 137.4 \\
72 & 1159 & 192.4 & 208.0 & 195.0 & 206.1 \\
\hline
\end{tabular}

sion of the GFDL model (GFDN) was transferred to the U.S. Navy in 1996 (Rennick 1999) to provide forecast guidance in the western Pacific. In the following year, the GFDN began to provide forecasts in the other ocean basins, including those in the Southern Hemisphere.

In a previous publication (Kurihara et al. 1998, hereafter KTB), details were presented about the version of the GFDL forecast system implemented operationally in 1995. This included the governing equations, the grid configuration, model physics, the time integration scheme, and the construction of the initial conditions. In addition, a detailed analysis of the overall model performance was presented for the very active 1995 hurricane season (the first year the model provided operational guidance to TPC). This version was a triply nested moveable mesh model with an outer mesh resolution of $1^{\circ}$ and with a finest resolution of $16^{\circ}$. Although the governing equations and time integration scheme are essentially unchanged since 1998 , numerous improvements to the model physics and the model's horizontal and vertical resolution have been made.

The purpose of this paper is to present a detailed summary of the various improvements and upgrades to the GFDL hurricane prediction system since KTB. This includes the transition of the model from an uncoupled atmospheric model to a coupled atmosphere-ocean model with a fully interactive ocean. Previous studies (Bender et al. 1993; Bender and Ginis 2000) confirmed the importance of the ocean coupling to intensity prediction with the GFDL hurricane model, particularly

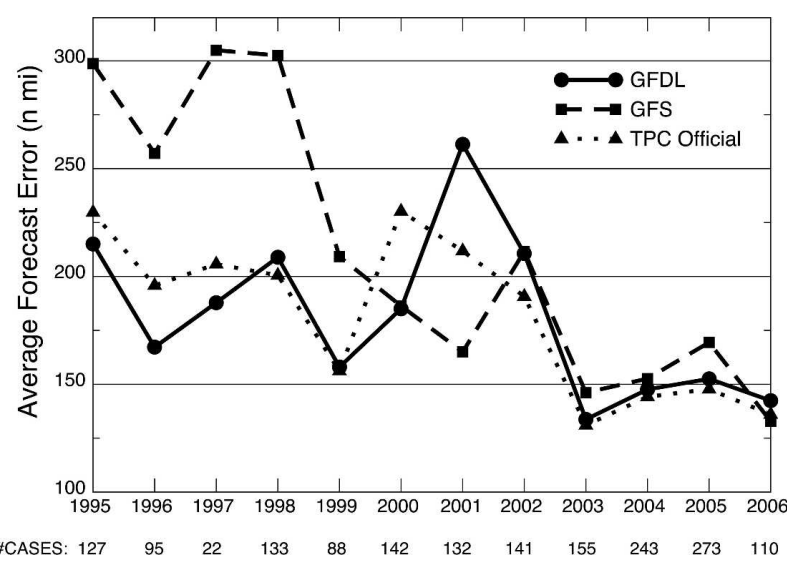

FIG. 1. The 72-h forecast error in the Atlantic basin for the GFDL model (solid line, circle) and NCEP's GFS model (dashed line, square), compared to the TPC official forecast (dotted line, triangle) for the years of 1995 through 2006.

for slower-moving storms. As increased computer power and resources became available for operations at the NWS's National Centers for Environmental Prediction (NCEP), the resolution of the outer grid of the GFDL model was doubled in 2002 from $1^{\circ}$ to $12^{\circ}$. This enabled the model to forecast the synoptic-scale features that determine the storm motion better. In 2003, an increase in the number of vertical levels from 18 to 42 was possible, along with major changes to the model physics after the computer resources available for operations were again greatly expanded. This resulted in the lowest track errors ever for the GFDL model (Fig. 1), with a 72-h error of only 137 nautical miles (nm). Two years later, after a new, more powerful computer was installed at NCEP, the model's finest resolution was doubled to $1 / 12^{\circ}$ in time for the 2005 recordbreaking Atlantic hurricane season. Finally, several major physics upgrades were implemented in 2006, along with improvements to the ocean initialization. The history of these upgrades clearly indicates how the improvements made to operational numerical weather prediction models are often dependent on the available computer resources and the limited time window that is allowed for each numerical forecast.

A historical perspective detailing the history of the GFDL model from its inception as a research model to its transfer to an operational forecast system will be presented in the following section (section 2). The purpose of this section is to outline the multiyear effort that it took to achieve this accomplishment. A summary of the various upgrades to the operational forecast system since 1998 will be presented next (section 3). This includes a summary of the ocean model and major improvements to the ocean initialization (sections 3d,e), particularly in the version that became operational in 
2006. In this section details of the grid configuration in the latest version of the model will be outlined, both for the atmospheric and ocean components. Comparison of the model performance between this latest version of the GFDL model and the previous version will be presented in section 4 , along with the summary of the model performance over the past 7 yr. Finally, some concluding thoughts will be presented in section 5 .

At the time of the writing of this paper, the nextgeneration nonhydrostatic Hurricane Weather, Research, and Forecasting (HWRF) model was being developed by NOAA scientists in collaboration with academia. To take advantage of the success of the GFDL model, the physics in the initial implementation of HWRF are being made as similar as possible to the latest version of the GFDL model physics detailed in this paper (Surgi et al. 2006).

\section{Historical perspective: Development of a hurricane modeling effort at GFDL}

The hurricane dynamics group at NOAA's GFDL was formed by Joe Smagorinsky in 1970 under the leadership of Yoshio Kurihara for the purpose of performing hurricane research through numerical modeling. An axisymmetric model was constructed the following year, and in 1973 the first experiments with a threedimensional model were made (Kurihara and Tuleya 1974). Two years later, a nested version of the model was developed, with movement capability introduced in 1978 (Kurihara and Bender 1980). Throughout the next decade, many idealized numerical experiments demonstrated the capability of this model to produce a realistic hurricane structure, although it would not be until the mid-1980s that real data simulations would be attempted (Tuleya 1988). Realistic behavior of tropical cyclones was reproduced by the model, including decay over land (Tuleya et al. 1984), sensitivity of intensity to sea surface temperatures (Tuleya and Kurihara 1982), effect of high mountains on storm motion and intensity (Bender et al. 1987), and environmental influences on the storm behavior (Tuleya and Kurihara 1981). These results strongly suggested the potential of improving hurricane prediction with a comprehensive threedimensional model. The hurricane model that eventually was made operational in 1995 was an outgrowth of this early research model.

In 1985, the National Meteorological Center (NMC) director Bill Bonner and Yoshio Kurihara, the head of the hurricane modeling group at GFDL, began to discuss the potential of an operational application of the GFDL hurricane model. It was recognized that a multiyear effort by scientists at GFDL would be necessary to transfer a model developed for basic research into a robust modeling system that could meet the rigorous demands of an operational environment. Indeed, the entire effort took nearly $10 \mathrm{yr}$. With the full support of the director of GFDL, Jerry Mahlman, GFDL's hurricane group began to address the problems that needed to be solved before the model could be applied for operational forecasting. In the next several years, an improved lateral boundary scheme was developed (Kurihara et al. 1989), a new mass initialization technique was formulated (Kurihara et al. 1993), and a land surface temperature prediction scheme with a full radiation package was introduced (Tuleya 1994). The prediction capability of the upgraded model using real data was investigated in 1989 using the NMC global analysis data for two cases of Hurricane Gloria from 1985 (Kurihara et al. 1990). Encouraged by the results, a major effort was undertaken over the next several years to develop a technique to insert a more realistic and model-consistent vortex into the global analysis. This new vortex initialization system was completed by 1991 (Kurihara et al. 1993) and was later improved in 1994 (Kurihara et al. 1995).

The new GFDL system was tested on a limited number of cases from the 1991 Atlantic hurricane season using the NMC global analysis and forecast model [Aviation Model (AVN)] as the initial and boundary condition. Although the number of cases was small, superior skill was demonstrated compared to the other track guidance available. Acting upon the recommendations of the NMC director Ron McPherson, and the director and assistant director of NMC's Development Branch, Eugenia Kalnay and Steve Lord, the GFDL group agreed to evaluate the new modeling system on more cases over a multiple season sample. As additional near-real-time forecasts were made at GFDL during the 1992 (18 cases) and 1993 hurricane seasons (72 cases), substantial track skill continued to be demonstrated by the model, which correctly forecasted the landfall of Hurricane Andrew in western Louisiana, the sharp turn of Hurricane Iniki toward the island of Kauai, Hawaii, and the sharp recurvature of Hurricane Emily away from North Carolina's Outer Banks. These successes resulted in a decision in late 1993 to transfer the GFDL hurricane forecast system to NMC's computer system for parallel real-time testing against the National Weather Service's then-operational QuasiLangrangian Model (QLM). This involved a substantial coding effort over the next 6 months to optimize the model's throughput efficiency in order to meet the rigorous timing requirements of NMC's operational environment, which required a 72-h prediction to be com- 
TABLE 2. Upgrades to the GFDL forecast system made operational since 1998.

\begin{tabular}{|c|c|}
\hline $\begin{array}{l}\text { Year of } \\
\text { upgrade }\end{array}$ & Operational upgrades to the GFDL forecast system \\
\hline 1998 & $\begin{array}{l}\text { Beta gyre in specified vortex replaced by asymmetries obtained from previous } 12 \text {-h forecast } \\
\text { Vertical distribution of target wind in vortex spinup made a function of storm intensity }\end{array}$ \\
\hline 2001 & $\begin{array}{l}\text { Atmospheric model coupled to a high-resolution version of the POM } \\
\text { Upgrade of vertical diffusion from level-2.0 to }-2.5 \text { Mellor and Yamada closure scheme } \\
\text { Effect of dissipative heating added }\end{array}$ \\
\hline 2002 & $\begin{array}{l}\text { Increase of horizontal resolution in outer nest from } 1^{\circ} \text { to } 1 / 2^{\circ} \\
\text { Expansion of region covered by finest mesh (from } 5^{\circ} \text { square domain to } 11^{\circ} \text { ) } \\
\text { Modification of filter to remove global vortex in vortex initialization (enables more small-scale features in the global } \\
\text { analysis to be retained) } \\
\text { Improved vortex removal algorithm in initialization (less distortion of environmental fields) }\end{array}$ \\
\hline 2003 & $\begin{array}{l}\text { Increased vertical resolution (number of vertical levels increased from } 18 \text { to } 42 \text { ) } \\
\text { Kurihara cumulus parameterization replaced by SAS } \\
\text { Mellor and Yamada level-2.5 vertical diffusion scheme replaced by Troen and Mahrt (1986) nonlocal scheme } \\
\text { Improved mass initialization for temperature and sea level pressure (reduced noise over mountains) } \\
\text { Improved pressure gradient computation (use of virtual temperature) } \\
\text { Effect of evaporation of rain added } \\
\text { Further refinements to vortex removal algorithm in initialization } \\
\text { More consistent target wind in vortex initialization } \\
\text { Ocean coupling expanded to entire ocean domain } \\
\text { Gulf Stream assimilation added to ocean initialization }\end{array}$ \\
\hline 2004 & Introduction of one-dimensional coupling in the eastern Pacific basin \\
\hline 2005 & $\begin{array}{l}\text { Addition of third nest with } 1 / 12^{\circ} \text { resolution } \\
\text { Improved vortex spinup with model physics consistent with } 3 \mathrm{D} \text { model } \\
\text { Elimination of mass initialization step }\end{array}$ \\
\hline 2006 & $\begin{array}{l}\text { Replaced the large-scale condensation scheme with Ferrier cloud microphysics package } \\
\text { Improved air-sea momentum flux parameterization in strong wind conditions } \\
\text { Assimilation of the Loop Current and warm-core eddies in Gulf of Mexico added to ocean initial condition }\end{array}$ \\
\hline
\end{tabular}

pleted in less than 20 min (Kurihara et al. 1998). With nearly a factor of 18 speedup gained by enabling the model to run efficiently on multiple processors, the GFDL forecast system was able to run in parallel test mode at NMC for most forecasts during the entire 1994 Atlantic and eastern Pacific hurricane season. After the postseason analysis demonstrated a $20 \%$ reduction in track error at $72 \mathrm{~h}$ compared to the QLM, the GFDL Hurricane Prediction System was adopted by the National Weather Service and made fully operational, in time for the 1995 hurricane season. As previously discussed, details of this forecast system were presented in KTB. The next section will summarize the improvements in the modeling system since that time.

\section{Advances in the GFDL hurricane model}

As previously discussed, the culmination of a multiyear effort at GFDL resulted in the successful operational implementation of the GFDL hurricane system at NCEP in 1995, with details of the model and the entire prediction system summarized in KTB. Specific details of the initialization steps were outlined in Kurihara et al. (1993, 1995). Model physics included cumu- lus parameterization described by Kurihara (1973), with additional modifications (Kurihara and Bender 1980, their appendix C), a Monin-Obukhov scheme for the surface flux calculation, and the Mellor and Yamada $(1974,1982)$ level-two turbulence closure scheme for the vertical diffusion.

Since its operational implementation in 1995, the GFDL forecast system has undergone five major upgrades in 2001, 2002, 2003, 2005, and, most recently, 2006. These involved three major changes to the GFDL atmospheric physics made in 2001, 2003, and 2006, with two major changes to the horizontal grid configuration in 2002 and 2005 and an increase of vertical resolution in 2003. Modifications to the initialization were also implemented in 1998, 2002, and 2003. A summary of all of these changes is presented in Table 2. The changes to the initialization are outlined in section $3 \mathrm{a}$, with the upgrades to the atmosphere model physics and changes to the grid configuration the topics of sections 3b,c, respectively. In 2001, the atmospheric model was coupled to the Princeton Ocean Model (POM). A summary of the ocean component of the coupled system and upgrades to that system will be discussed separately in sections $3 \mathrm{~d}$,e, respectively. 


\section{a. Improvements in the atmospheric initialization}

Two changes to the vortex initialization scheme detailed in Kurihara et al. $(1993,1995)$ were implemented in 1998 in order to improve the storm structure, particularly for weak or asymmetric storms. First, the betagyre asymmetry in the initial vortex, generated by solving the barotropic vorticity equation, was replaced by a technique developed to estimate the hurricane vortex asymmetries by using forecast fields obtained from the previous 12-h forecast. In this new approach, the GFDL filters (Kurihara et al. 1995, their section 2) are used to remove the vortex of the 12 -h forecast fields from the forecast initialized $12 \mathrm{~h}$ earlier. (It was found that by 12 $\mathrm{h}$ the model storm has adjusted well to the environment.) Next, azimuthal means of all prognostic variables (both horizontal components of the winds, temperature, mixing ratios, and surface pressure) are computed at each grid point of the vortex and each vertical model level. The means for all of the variables are computed along a $120^{\circ}$ arc, relative to the storm center, with the arc centered at each point. The mean is then subtracted from the value at each point to produce a full three-dimensional array of asymmetries. The resulting asymmetric disturbance field is added to the initial axisymmetric vortex at each grid point for all of the variables. The second change involved the vertical distribution of the target wind in the vortex initialization, which was made a function of the storm intensity. In particular, in this modified approach the depth of the storm was assumed to increase as a function of the TPC-reported maximum surface winds. These two modifications resulted in some track and intensity improvements at 12 and $24 \mathrm{~h}$.

In 2002, four improvements were made to the GFDL filters that remove the vortex from the global analysis. First, the filtering characteristics were modified to enable more of the smaller-scale features of the global analysis to be retained within the filtered region. This change was made because it was found that the original filtering system removed too much of the nonhurricane disturbance field in the global analysis, which may be important for the hurricane motion. Second, the algorithm that determined the radial extent of the vortex in the global analysis to be filtered was improved so that the vortex in the global analysis would be properly removed in each one of the storm quadrants. This change was particularly important after the vortex relocation system was introduced to NCEP's Global Forecast System (GFS) in 2000, resulting in a more asymmetric storm structure in some cases. Postseason analysis after the 2001 season indicated that in a number of cases the GFDL forecasts were degraded seriously because part of the vortex in the global analysis was not properly removed by the GFDL filters, causing the environmental wind field to occasionally become quite distorted near the storm. This contributed to the increased track error for the GFDL model in 2001 (Fig. 1). Many of the degraded forecasts were much improved with this correction. Third, the strength of the filter was made a function of two parameters - the size of the vortex being filtered from the global analysis, and the storm intensity defined by the central pressure reported by TPC. Finally, the amount of filtering was decreased in the vertical so that less of the GFS initial analysis in the upper levels was affected. For sigma levels above a certain sigma height no filtering was done. This height was set to either sigma $=0.12$ for observed central pressure less than $1000 \mathrm{hPa}$ or sigma $=0.17$ for central pressure greater than $1000 \mathrm{hPa}$. These limits were set by determining a reasonable upper limit for the maximum height of the vortex in the global analysis.

In the 2003 implementation, several additional improvements were made to the hurricane initialization. First, an improved mass initialization scheme was implemented for the computation of the sea level pressure and temperature. In this approach, which significantly reduced numerical noise over the mountainous terrain, the reverse balance equation was reformulated in an incremental form. Because a reasonably good balance should exist between the mass and wind fields in the global analysis, the rebalancing of the mass field was now restricted to the specified hurricane vortex added to the initial condition. The new formulation helped to eliminate the formation of spurious features, noted mostly in the sea level pressure field, which had occasionally developed in steep mountainous regions. It should be pointed out that with this technique, outside the region of the analysis that is modified by insertion of the hurricane vortex, the mass field is essentially the same as in the global analysis. This was consistent with the 2003 physics upgrade because the GFDL system adopted nearly the same moist and boundary layer physics as the GFS global model and had a similar horizontal resolution in the outer nest. This upgrade helped to minimize the mass and wind field adjustment at the start of the forecast.

During the 2004 Atlantic hurricane season tests on over 110 cases were conducted to determine if the mass initialization step could be eliminated in future implementations. When the mass initialization was removed it was found that the fields, even within the storm region, went through surprisingly little adjustment, and the overall track error was reduced about $6 \%$ through 3 days. The track improvements were largest in the Gulf of Mexico, suggesting that some valuable obser- 
vations in the mass fields could be better utilized running directly from the global temperature and surface pressure fields. The reduction in track error was statistically significant at the $90 \%$ level through $48 \mathrm{~h}$, and this change was operationally implemented in 2005 (Table 2). In the 2005 implementation, another upgrade to the vortex initialization involved the implementation of the physics identical to those used in the full threedimensional model.

\section{b. Advancements in the atmospheric physics}

\section{1) 2001 PHYSICS UPGRADE}

As outlined in Table 2, in the 2001 upgrade the coupling of the atmospheric model with the POM became operational after several years of testing on a large number of cases in the Atlantic basin (Bender and Ginis 2000). The second major physics change made in 2001 involved the Mellor and Yamada (1982) level-2 turbulence closure scheme for the vertical diffusion, which was upgraded to level 2.5. In this higher-order closure scheme, the turbulent kinetic energy (TKE) was computed using an equation for the tendency of TKE (Holt and Raman 1988). This turbulent mixing scheme remained operational in the GFDL model for the 2001 and 2002 hurricane seasons.

Bister and Emanuel (1998) demonstrated that the inclusion of dissipative heating could make a significant impact on the intensity forecasts of tropical cyclones, with the potential to increase the maximum wind speeds by up to $20 \%$. The effect of dissipative heating in the GFDL model was also implemented in 2001, formulated based on the dissipation of TKE, which is expressed as a function of the (TKE) ${ }^{3 / 2}$ [e.g., Sharan and Gopalkrishnan 1997, their Eq. (15)].

\section{2) 2003 PHYSICS UPGRADE}

The upgrades to the GFDL hurricane forecast system in 2003 involved the most substantial changes to the model physics since its operational implementation in 1995 and were intended to make the model more compatible with NCEP's Global Forecast System. The Kurihara (1973) convective parameterization was replaced by the simplified Arakawa-Schubert (SAS) cumulus parameterization used in the GFS (Pan and Wu 1995; Pan 2003). This scheme, which is based on Arakawa and Schubert (1974) and simplified by Grell (1993), was made operational in NCEP's global model in 1995. A major simplification to the original Arakawa-Shubert scheme was made by considering a random cloud top at a specified time increment (4 min for the GFDL hurricane model), and not the spectrum of cloud sizes, as in the computationally expensive original Arakawa and Schubert (1974). As in Pan (2003), the mass fluxes induced in the updrafts and the downdrafts are allowed to transport momentum. This introduction of the effect of momentum mixing was made operational in NCEP's GFS model in May 2001 and greatly reduced the generation of spurious vortices in the global model. In sensitivity experiments both with and without the momentum mixing in the GFDL model it was found that including it in the SAS parameterization resulted in a significant positive impact on the hurricane tracks.

Along with the implementation into the GFDL model of NCEP's simplified Arakawa-Schubert scheme, the Mellor and Yamada level-2.5 diffusion scheme was replaced with a nonlocal boundary layer parameterization based on the Troen and Mahrt (1986) concept that was implemented in the NCEP global modeling system in October 1995 (Hong and Pan 1996). In this parameterization, the boundary layer height is determined from the critical bulk Richardson number. The vertical profiles of the eddy diffusivities are determined as a cubic function of the boundary layer height.

The 2003 physics upgrade also included the introduction of the evaporation of falling rain in the large-scale condensation package. The implemented scheme was similar to the treatment of evaporation of falling rain in the SAS scheme, and is essentially the same as that in the GFS.

\section{3) 2006 PHYSICS UPGRADE}

The third major physics upgrade to the GFDL model was made in 2006. In the previous versions of the model, a large-scale condensation package was used that assumed all condensed water would immediately fall as rain after a threshold humidity was reached. Although it was recognized that this very simple scheme likely contributed to the model's severe positive intensity bias in sheared situations, it was computationally too expensive to run the model with more advanced cloud physics. With improved computer capabilities and improvement in the model efficiency, the largescale condensation scheme was replaced in 2006 with a cloud microphysics package.

The microphysics package is the version that has been operational in the NCEP regional Eta Model since November 2001 (Ferrier et al. 2002; Ferrier 2005). The scheme predicts the following four classes of hydrometeors: suspended cloud liquid water droplets, rainwater, large ice particles, which include snow and graupel, and small ice particles. A simplification is made as in Ferrier (2005) in order to further optimize the code by treating only the sum of the four hydrome- 
teor classes (referred to as the total condensate) in the advection of the cloud species in both the horizontal and vertical directions. It should be pointed out that this scheme was designed to incorporate many of the basic microphysical processes found in schemes that are more complex, but using far less computer resources. In particular, the four hydrometeor species are allowed to grow and shrink in size. Additionally, the scheme uses an ice density to account for the different forms of frozen precipitation and the fall speeds are a function of the hydrometeor size and type.

One of the novel aspects of the Ferrier (2005) scheme is that it includes a rime factor that allows for a continuum of rimed ice growth from snow to graupel and sleet. The scheme allows for the coexistence and interaction of all forms of liquid and frozen cloud and precipitation particles under certain conditions. During the evaluation of the Ferrier package in the GFDL hurricane model, a range of values from 0.11 to $0.53 \mathrm{~g} \mathrm{~m}^{-3}$ was tested for the autoconversion threshold. It was found that a value of $0.25 \mathrm{~g} \mathrm{~m}^{-3}$ gave the best results, especially for the prediction of the storm intensity. Another important parameter is the relative humidity threshold for condensation. In the Eta Model the value was set to $97.7 \%$. After extensive testing, the value of $97.5 \%$ was adopted in the hurricane model in the free atmosphere, with a $100 \%$ threshold retained in the boundary layer.

The second important upgrade to the physics in 2006 was an improved parameterization of the air-sea momentum fluxes. The air-sea flux calculations in the original GFDL model were made using bulk parameterization based on the Monin-Obukhov similarity theory (Kurihara and Tuleya 1974). The roughness length $\left(z_{0}\right)$ was calculated using a constant Charnock coefficient or nondimensional roughness length $\left(z_{\mathrm{ch}}\right)$, defined as

$$
z_{\mathrm{ch}}=\frac{z_{0} g}{u_{*}^{2}}=0.0185
$$

where $u_{*}$ is the friction velocity and $g$ is the gravitational acceleration. In this formulation, the neutral drag coefficient $C_{d}$ is defined as

$$
C_{d}=\kappa^{2}\left(\ln \frac{10 \mathrm{~m}}{z_{0}}\right)^{-2}
$$

where $\kappa$ is the von Kármán constant (0.4), and the neutral heat and humidity coefficients (assumed to be equal, $C_{k}$ ) are expressed as

$$
C_{k}=k^{2}\left(\ln \frac{10 \mathrm{~m}}{z_{0}}\right)^{-1}\left(\ln \frac{10 \mathrm{~m}}{z_{T}}\right)^{-1},
$$

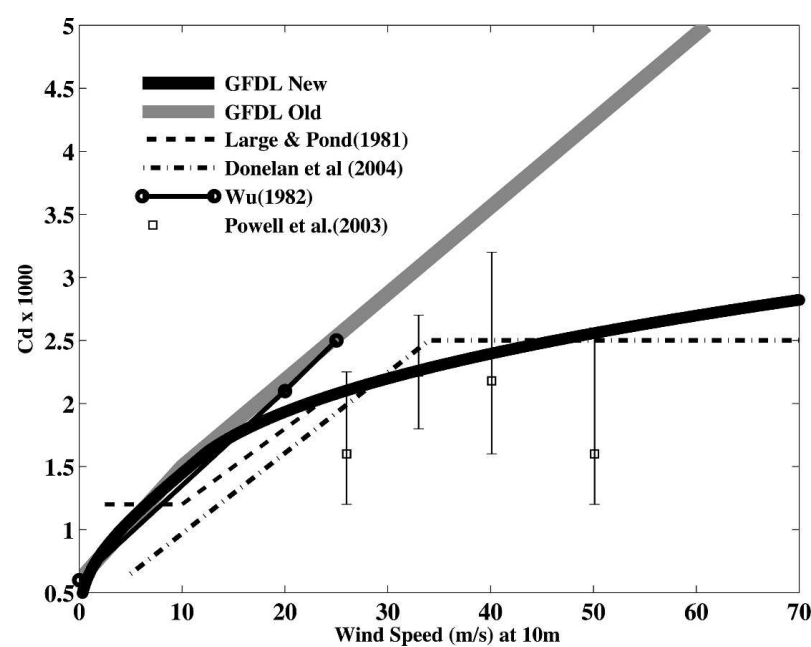

FIG. 2. Neutral drag coefficient $C_{d}$ vs 10 -m wind speed; original operational GFDL hurricane model (thick gray line), 2006 GFDL model (thick black line), according to Wu (1982) (black line with circles), according to Large and Pond (1981) (dashed line), according to Donelan et al. (2004) (dashed-dotted line), averaged values from data of Powell et al. (2003) (squared), and the range of estimates based on $95 \%$ confidence (vertical bars).

where $z_{T}$ is the roughness length for heat and humidity fluxes. Both $z_{0}$ and $z_{T}$ are determined from Charnock's relation (1), $0.0185 u_{*}^{2} / g$. We should note that in the GFDL model $C_{d}$ and $C_{k}$ are calculated at the lowest model level, which is $35 \mathrm{~m}$. Here we use the customary reference height of $10 \mathrm{~m}$ in order to compare the GFDL formulation with other studies. In the GFDL model, the $10-\mathrm{m}$ wind speed is calculated from the $35-\mathrm{m}$ wind speed using the Monin-Obukhov similarity theory.

In the above formulation both $C_{d}$ and $C_{k}$ increase approximately linearly with wind speed (Fig. 2). This behavior is consistent with field measurements in weakto-moderate wind regimes less than $20 \mathrm{~m} \mathrm{~s}^{-1}$ (DeCosmo et al. 1996; Zeng et al. 1998). Recent experimental and theoretical studies indicate that at high wind speeds $C_{d}$ ceases to increase with wind speed (Powell et al. 2003; Donelan et al. 2004; Emanuel 2003; Moon et al. 2004a,b; Makin 2005; Black et al. 2007), although physical explanations vary. This implies that the original GFDL parameterization of $C_{d}$ overestimated the surface drag at high wind speeds and was one of the reasons the GFDL forecasts had a tendency to underestimate the surface wind speed for a given central pressure in strong hurricanes (Ginis et al. 2004, see their Fig. 2).

In the new momentum flux parameterization, $z_{0}$ is derived from coupled wind-wave (CWW) model simulations in hurricane conditions (Moon et al. 2007). The details of the CWW model is described in Moon et al. (2004a,b). The simulations to derive $z_{0}$ were conducted 
independently from the GFDL hurricane system. Rather, high-resolution wind fields produced by the Hurricane Research Division (HRD) tropical cyclone observing system (Powell et al. 1998) were used. In the CWW model, the surface wave directional frequency spectrum near the spectral peak is calculated using the third-generation wave model WAVEWATCH III (Tolman 2002) model and the high-frequency part of the spectrum is parameterized using the theoretical model of Hara and Belcher (2002). The complete wave spectrum is then introduced to the wave boundary layer model of Hara and Belcher (2004) to estimate $z_{0}$ at different wind and wave conditions. The CWW model treats the wind stress as a vector quantity in order to incorporate the influence of dominant waves that propagate at a large angle to the local wind.

The new roughness length has been derived from CWW simulations of 10 hurricanes that occurred in the Atlantic Ocean during 1998-2003 (Moon et al. 2007) and is expressed as a function of wind speed,

$$
\begin{aligned}
& z_{0}=\frac{0.0185}{g}\left(0.001 W^{2}+0.028 W\right)^{2}, \quad W \leq 12.5 \mathrm{~m} \mathrm{~s}^{-1}, \\
& z_{0}=(0.085 W-0.58) \times 10^{-3}, \quad W>12.5 \mathrm{~m} \mathrm{~s}^{-1},
\end{aligned}
$$

where $W$ is the wind speed at $10-\mathrm{m}$ height $\left(\mathrm{m} \mathrm{s}^{-1}\right)$.

Figure 2 compares the neutral drag coefficient $C_{d}$ estimated from the new and old GFDL model formulations and the results from $\mathrm{Wu}$ (1982), Large and Pond (1981), Donelan et al. (2004), and Powell et al. (2003). For $W \leq 12.5 \mathrm{~m} \mathrm{~s}^{-1}$, the new $C_{d}$ represents a monotonic increase with wind speed as in the original GFDL model and is similar to that of $\mathrm{Wu}$ (1982). However, it is slightly higher than those of Large and Pond (1981) and Donelan et al. (2004). For $W>12.5 \mathrm{~m} \mathrm{~s}^{-1}$, the new $C_{d}$ tends to level off between 20 and $30 \mathrm{~m} \mathrm{~s}^{-1}$. This is similar to the trend observed by Donelan et al. (2004) and Black et al. (2007) and is within the error bars estimated by Powell et al. (2003), although it is somewhat higher than their averaged values. At $60 \mathrm{~m} \mathrm{~s}^{-1}$ wind speed, the new $C_{d}$ is half of the value used in the original GFDL model.

In the 2006 GFDL model upgrade, the heat flux parameterization (3) remained the same as in the original formulation, with $z_{T}$ defined from Charnock's relation (1), where the roughness length $z_{0}$ has been replaced by the new Eqs. (4)-(5). Figure 3 shows the $C_{d}$ and $C_{k}$, in the 2006 GFDL model as well as the ratio $C_{k} / C_{d}$, as a function of wind speed. The ratio lies in the range of $0.7-1.3$ and increases as wind speed increases. This
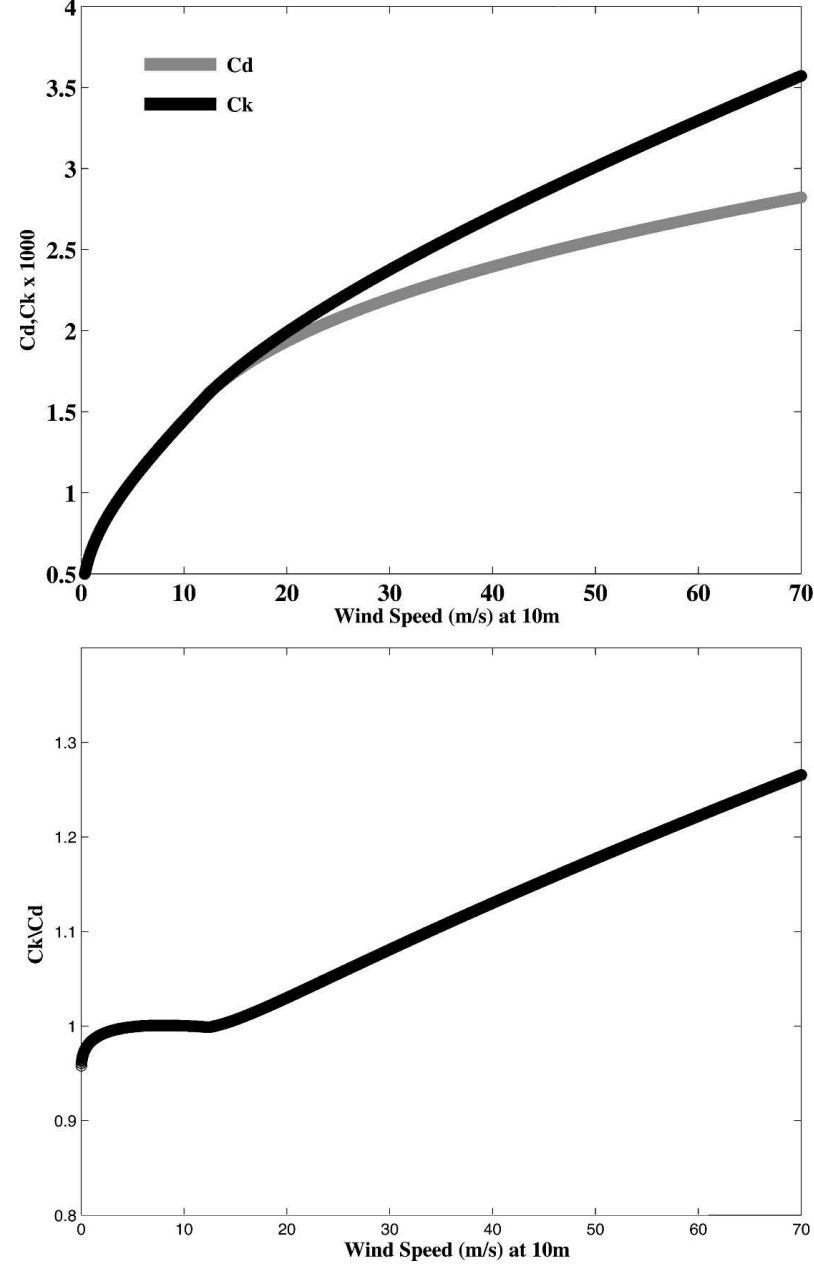

FIG. 3. (top) Neutral heat and humidity exchange coefficient $\left(C_{k}\right)$ and drag $\left(C_{d}\right)$ coefficient and (bottom) their ratio $\left(C_{k} / C_{d}\right)$ plotted against wind speed at $10 \mathrm{~m}$ in the 2006 GFDL hurricane model.

trend is qualitatively consistent with Emanuel (1995) who found, using a hurricane model, that $C_{k} / C_{d}$ increases from 0.75 to 1.5 when a hurricane intensifies. Estimations of $C_{k}$ in the recent Coupled Boundary Layers Air-Sea Transfer (CBLAST) field experiment indicate a constant value of $1.1 \times 10^{-3}$, up to hurricaneforce wind speeds (Black et al. 2007). This is significantly lower than the values of $C_{k}$ shown in Fig. 3. It is certainly possible that the values of $z_{T}$ at high wind speeds presently used in the GFDL model are overestimated. Nevertheless, our attempts to apply other available relationships in the literature for $z_{T}$ indicated great sensitivity of model-simulated hurricanes to this parameter, and generally led to significant degradation of the GFDL model forecast skill, especially for strong hurricanes. The parameterization of heat fluxes involves consideration of microscale physical processes 
near the sea surface, including spray production and advection, the characteristics of the interfacial sublayers, and the character of the surface sea state, including wave breaking. All of these processes are not included in the 2006 GFDL model physics because their understanding is still severely limited, and there are no in situ measurements of ocean surface characteristics at wind speeds greater than $35 \mathrm{~m} \mathrm{~s}^{-1}$.

\section{c. Changes in the atmospheric model grid configurations}

After the operational implementation of the GFDL system in 1995, the horizontal grid configuration remained the same for the first $7 \mathrm{yr}$. A major change to the model grid configuration was made in 2002 and the three-nest grid configuration was replaced by a twonest model (Table 3). The resolution of the outer nest was increased from $1^{\circ}$ to $12^{\circ}$ to enable the environmental and synoptic fields to be better resolved. The size of the innermost nest with $1 / 6^{\circ}$ resolution was expanded from $5^{\circ}$ to $11^{\circ}$ for better simulation of the hurricane and environmental interaction. Past studies (e.g., Wu and Emanuel 1994) have suggested this may play an important role in forecasting the motion of tropical cyclones.

As previously mentioned, increases in the computer power at NCEP allowed for further increases in the vertical and horizontal resolution of the operational model. In 2003, the number of vertical levels in the GFDL model was increased from 18 to 42, which was the first increase in the number of levels since the model became operational in 1995. The vertical levels chosen were the same as those used in the GFS in 2003. A summary of the new levels and their corresponding height is given in Fig. 4. Note the extensive number of vertical levels in the boundary layer (Fig. 4b), which is essential to resolve the important boundary processes that can be particularly critical in the forecasting of the storm intensity properly (Kimball and Dougherty 2006). The GFDL forecast system underwent a second major upgrade in the horizontal grid configuration before the start of the 2005 hurricane season, with the addition of a third nest with $1 / 12^{\circ}$ resolution. With this doubling of the finest resolution, it was possible to resolve much more of the finer-detailed hurricane structure and the interaction of the vortex with the surrounding environment. The details of the new grid configuration are presented in Table 4.

\section{d. Design of the atmosphere-ocean coupled system}

In 2001, the atmospheric model was coupled to a high-resolution version of the POM incorporating the effect of the tropical cyclone-ocean interaction into the
TABLE 3. Grid system made operational in 2002.

\begin{tabular}{|c|c|c|c|c|c|c|}
\hline \multirow[b]{3}{*}{ Mesh } & \multicolumn{6}{|c|}{ Domain size } \\
\hline & \multirow{2}{*}{$\begin{array}{c}\text { Grid } \\
\text { resolution } \\
\left(^{\circ}\right)\end{array}$} & \multicolumn{2}{|c|}{ Longitude } & \multicolumn{2}{|c|}{ Latitude } & \multirow{2}{*}{$\begin{array}{l}\text { Time } \\
\text { step } \\
\text { (s) }\end{array}$} \\
\hline & & $\left({ }^{\circ}\right)$ & (points) & $\left(^{\circ}\right)$ & (points) & \\
\hline 1 & $1 / 2$ & 75 & $(150)$ & 75 & $(150)$ & 60 \\
\hline 2 & $1 / 6$ & 11 & $(66)$ & 11 & $(66)$ & 20 \\
\hline
\end{tabular}

forecast system. This was the culmination of a 10-yr effort that began in 1991 at GFDL. In early studies in which the GFDL model was coupled to a multilayer primitive-equation ocean model (Bender et al. 1993), an idealized set of experiments was performed with various basic flows to investigate the impact of ocean interaction on storm intensity and track. It was found that the cooling of the ocean induced by the tropical cyclone has an increased impact on storm intensity as the storm's translational speed is decreased. Next, the effect of hurricane-ocean interaction was investigated with real data studies (Bender and Ginis 2000). These studies also confirmed that the GFDL model intensity forecasts could be improved if this effect was included. In real case studies, significantly improved intensity prediction was achieved for Hurricanes Felix, Fran, Opal, and Gilbert (Bender and Ginis 2000). The GFDL hurricane-ocean coupled model was tested on 163 cases during the 1995-98 hurricane seasons with significantly improved intensity forecasts obtained, particularly for the central pressure, which showed reductions in forecast errors of $26 \%$ (Ginis et al. 1999). Based on these results, the coupled model replaced the operational uncoupled version in 2001.

POM is a three-dimensional, primitive-equation model with complete thermohaline dynamics, a sigma vertical coordinate system, and a free surface (Blumberg and Mellor 1987). The specific model details have been outlined extensively in Bender and Ginis (2000). In the first operational implementation of the GFDL coupled system in 2001, for computational efficiency the Atlantic basin was divided into the following three overlapping but separate integration domains: the Gulf of Mexico, western Atlantic, and eastern Atlantic. One domain is chosen automatically at the beginning of each forecast, depending on the initial position and predicted track from the previous forecast. The use of separate regions resulted in an occasional loss of ocean coupling when a hurricane moved from one region to another during a forecast. To help rectify this problem, a major change in the ocean model computational domains was introduced in 2003 when the Gulf of Mexico and western Atlantic domains were combined into a single domain. In the current configuration (Fig. 5), the 
GFDL MODEL SIGMA LEVEL DISTRIBTUION 42 LEVEL MODEL

\begin{tabular}{|c|c|}
\hline \multirow[t]{4}{*}{20300 meters } & $\begin{array}{l}.04 \\
.06\end{array}$ \\
\hline & .09 \\
\hline & $\begin{array}{l}-15 \\
-.15 \\
18\end{array}$ \\
\hline & .20 \\
\hline \multirow[t]{3}{*}{10200 meters } & .27 \\
\hline & $\begin{array}{l}.30 \\
34\end{array}$ \\
\hline & .38 \\
\hline \multirow[t]{3}{*}{7025 meters } & .42 \\
\hline & .46 \\
\hline & .50 \\
\hline \multirow{2}{*}{5020 meters } & .54 \\
\hline & .69 \\
\hline 3400 meters & .67 \\
\hline \multirow{2}{*}{2550 meters } & 70 \\
\hline & .77 \\
\hline \multirow[t]{2}{*}{1860 meters } & .804 \\
\hline & .832 \\
\hline 1300 meters & .859 \\
\hline \multirow[t]{3}{*}{1080 meters } & .882 \\
\hline & .903 \\
\hline & 922 \\
\hline \multirow[t]{3}{*}{500 meters } & .937 \\
\hline & .953 \\
\hline & .966. \\
\hline \multirow[t]{2}{*}{200 meters } & .977 \\
\hline & $\begin{array}{l}.987 \\
.996\end{array}$ \\
\hline
\end{tabular}

FIG. 4. Summary of the new 42-sigma-level vertical coordinate system made operational in 2003. The actual sigma levels are indicated on the right side, with the approximate height of 11 of the sigma levels indicated on the left side.

POM includes two overlapping but separate domains in the Atlantic basin-one each for the eastern Atlantic and western Atlantic-which are selected automatically, depending on the location of the forecast storm. The horizontal grid resolution of each ocean domain is $16^{\circ}$, with 23 sigma levels in the vertical. Most of the Atlantic basin in which TPC has forecast responsibility is covered by one of the two model domains.

In 2004, ocean coupling was introduced in the eastern
Pacific where, for computational efficiency, the GFDL model was coupled with a one-dimensional ocean model derived from the three-dimensional POM. In contrast to the Atlantic basin, there are no significant oceanic fronts in the eastern Pacific, and thus the impact of the background three-dimensional currents on the oceanic response can be neglected. Both coupled hurricane-ocean simulations by Emanuel (1999) and our own testing with the GFDL system in- 
TABLE 4. Grid system made operational in 2005.

\begin{tabular}{|c|c|c|c|c|c|c|}
\hline \multirow[b]{3}{*}{ Mesh } & \multicolumn{6}{|c|}{ Domain size } \\
\hline & \multirow{2}{*}{$\begin{array}{c}\text { Grid } \\
\text { resolution } \\
\left(^{\circ}\right)\end{array}$} & \multicolumn{2}{|c|}{ Longitude } & \multicolumn{2}{|c|}{ Latitude } & \multirow{2}{*}{$\begin{array}{l}\text { Time } \\
\text { step } \\
\text { (s) }\end{array}$} \\
\hline & & $\left(^{\circ}\right)$ & (points) & $\left({ }^{\circ}\right)$ & (points) & \\
\hline 1 & $1 / 2$ & 75 & $(150)$ & 75 & $(150)$ & 60 \\
\hline 2 & $1 / 6$ & 11 & (66) & 11 & (66) & 20 \\
\hline 3 & $1 / 12$ & 5 & (60) & 5 & $(60)$ & 10 \\
\hline
\end{tabular}

dicate that the one-dimensional ocean model provides adequate simulations of the sea surface temperature response to the hurricane under its eyewall, where the air-sea interaction is critical for hurricane intensity. The eastern Pacific Ocean model is configured on a $40^{\circ} \times 40^{\circ}$ relocatable grid, with a horizontal resolution of $16^{\circ}$ and 16 sigma levels. The center of the grid is determined automatically at the beginning of each forecast and coincides with the center of the GFDL hurricane model's outer mesh.

The method for coupling between the GFDL and POM models is described in detail by Bender and Ginis (2000). Briefly, during the period of one ocean model time step the atmospheric model is integrated with its own time steps, keeping the SST constant. The computed wind stress, heat, moisture, and radiative fluxes are passed into the ocean model, which is then inte- grated one step, and a new SST is calculated. The new SST is used in the ensuing time steps of the atmospheric model. In regions outside of the ocean domains, the SST field remains fixed in time and is the same as the SST in the GFS analysis. The transfer of the wind stress, heat, moisture, and radiative fluxes from the atmosphere grid to the ocean grid, as well as the transfer of the SST field from the ocean grid to the atmosphere grid, is accomplished through horizontal bilinear interpolation.

\section{e. Improvements to the ocean model initialization}

A realistic initialization of the 3D density and velocity fields in the ocean model is critical for proper simulation of the ocean response in the coupled hurricaneocean system. This is because the sea surface temperature response to the hurricane winds is very sensitive to the upper-ocean structure (Ginis 2002). In the beginning of each GFDL coupled model forecast, the POM is initialized by a diagnostic and prognostic spinup of the ocean circulation using available climatological ocean data in combination with the real-time data. The initialization procedure that was implemented into the 2001 version of the operational GFDL model is outlined in Bender and Ginis (2000). From 2002 to 2006, several upgrades were made, including an improved ini-

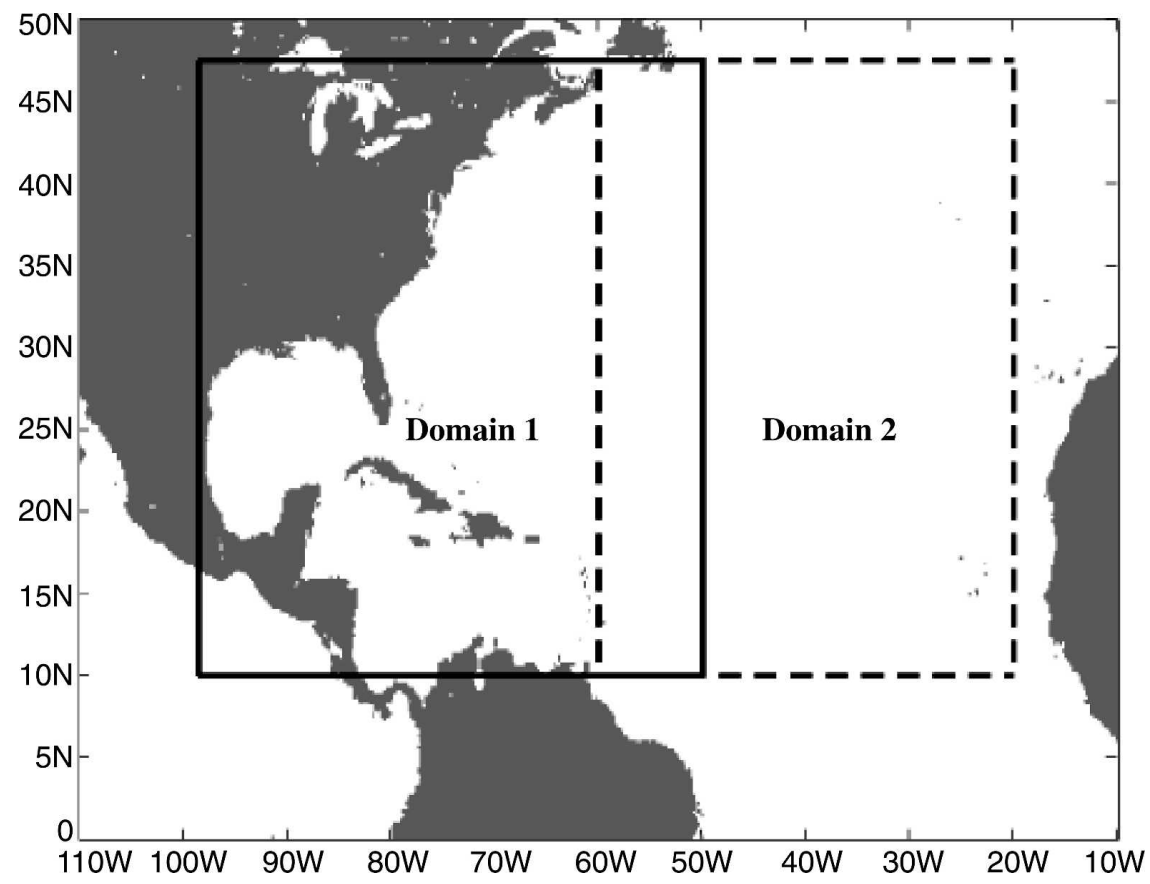

FIG. 5. The two computational domains in the ocean model in the GFDL coupled system. One domain is chosen automatically at the beginning of each forecast, depending on the initial position and predicted track from the previous forecast. 
tialization of the structure and position of the Gulf Stream in 2003. A major upgrade to the ocean model initialization was introduced in 2006. The essence of this upgrade is to improve initialization of oceanic fronts and eddies and their structures as realistically as possible at the beginning of each GFDL forecast.

The 2006 ocean initialization method, described in detail in Falkovich et al. (2005) and Yablonsky and Ginis (2008), improves upon the representation of the Loop Current and warm-core eddies that are shed by the Loop Current in the Gulf of Mexico. It is based on a feature-modeling approach, which was originally introduced by Robinson et al. (1989) and Lozano et al. (1996) and was successfully used for modeling and forecasting the Gulf Stream and oceanic eddies (Robinson and Gangopadhyay 1997). The main assumption in this method is that the cross-frontal temperature, salinity, and velocity structures in the upper and main thermocline do not change significantly along a strong oceanic front. This assumption is well supported by data obtained in specialized field experiments (Halkin and Rossby 1985; Leaman et al. 1989). While previous feature models used analytical formulas to represent frontal structures, the procedure implemented in the GFDL coupled system uses an innovative method of crossfrontal "sharpening" of the background temperature and salinity fields, which is guided by observed cross sections obtained in specialized field experiments (Falkovich et al. 2005).

In the 2006 GFDL coupled hurricane system the ocean model is initialized from the Generalized Digital Environmental Model (GDEM) monthly ocean temperature and salinity climatology at $1 / 2^{\circ}$ grid resolution (Teague et al. 1990). Other ocean climatologies have been developed since this GDEM version, such as a newer GDEM climatology and a Levitus climatology, which both have $1 / 4^{\circ}$ grid spacing (NAVOCEANO 2006; Boyer and Levitus 1997). However, tests with these climatologies in the GFDL forecast system did not show increased skill over the original GDEM version. The first step in the initialization procedure involves specification of the position and shape of the Gulf Stream in the Atlantic and the Loop Current and warm-core eddies in the Gulf of Mexico. The Gulf Stream path west of Cape Hatteras (from $82^{\circ}$ to $75^{\circ} \mathrm{W}$ ) is specified using long-term-averaged data as described in Leaman et al. (1989). East of Cape Hatteras (from $75^{\circ}$ to $\left.50^{\circ} \mathrm{W}\right)$, we use Gulf Stream northern edge monthly data derived from satellite thermal infrared imageries (Cornillon and Watts 1987). The Loop Current and warm-core eddies are specified using nearreal-time satellite altimetry data, which are available at the Tropical Prediction Center (M. Mainelli 2007, personal communication). Next, the GDEM threedimensional temperature and salinity fields are modified by employing the sharpening procedure (Falkovich et al. 2005), followed by assimilation of the SST fields from the GFS analysis within the upper-ocean mixed layer, as described in Bender and Ginis (2000). The ocean model then is integrated for 2 days for dynamic adjustment of the mass and current fields, keeping the SST constant. In the last step, the cold wake at the ocean surface and the currents produced by the hurricane prior to the beginning of the coupled model forecast are generated by running the POM for 3 days with the observed hurricane winds.

Figures 6 and 7 illustrate the capabilities of the ocean initialization procedure by comparing the observed and initialized Loop Current and warm-core ring in the Gulf of Mexico on 15 September 2005, 1 week in advance of Hurricane Rita. Figure 6 compares the depth of the $26^{\circ} \mathrm{C}$ isotherm, which was derived from satellite altimeter data with the pattern of the model-initialized temperature at a depth of $75 \mathrm{~m}$. The position and structure of the Loop Current and the warm-core ring are reproduced very well by the model initialization. On 15 September 2005, 19 airborne expendable bathythermograph (AXBT) instruments were dropped from aircraft in the Gulf of Mexico by scientists at the NOAA Hurricane Research Division (E. Uhlhorn 2006, personal communication), providing a unique opportunity to compare the simulated and observed temperature profiles. Figure 7 shows comparisons of the temperature profiles in two locations-one within the Loop Current and another within the warm-core eddy. The vertical temperature profiles after the model initialization are improved dramatically compared to those in the GDEM climatology, and are in good agreement with the AXBT profiles. Because the satellite altimeter data are not always able to identify the positions of the Loop Current and warm-core rings in the future accurately, the AXBTs may be assimilated directly into the ocean model in real time to obtain more accurate initial conditions (Yablonsky and Ginis 2008).

\section{Summary of the performance of the GFDL forecast system}

\section{a. Examples of the performance improvements over previous hurricane seasons}

One example that demonstrates the improvement in the GFDL track forecasts with the 2002 and 2003 upgrades can be seen in the predictions of Hurricane 

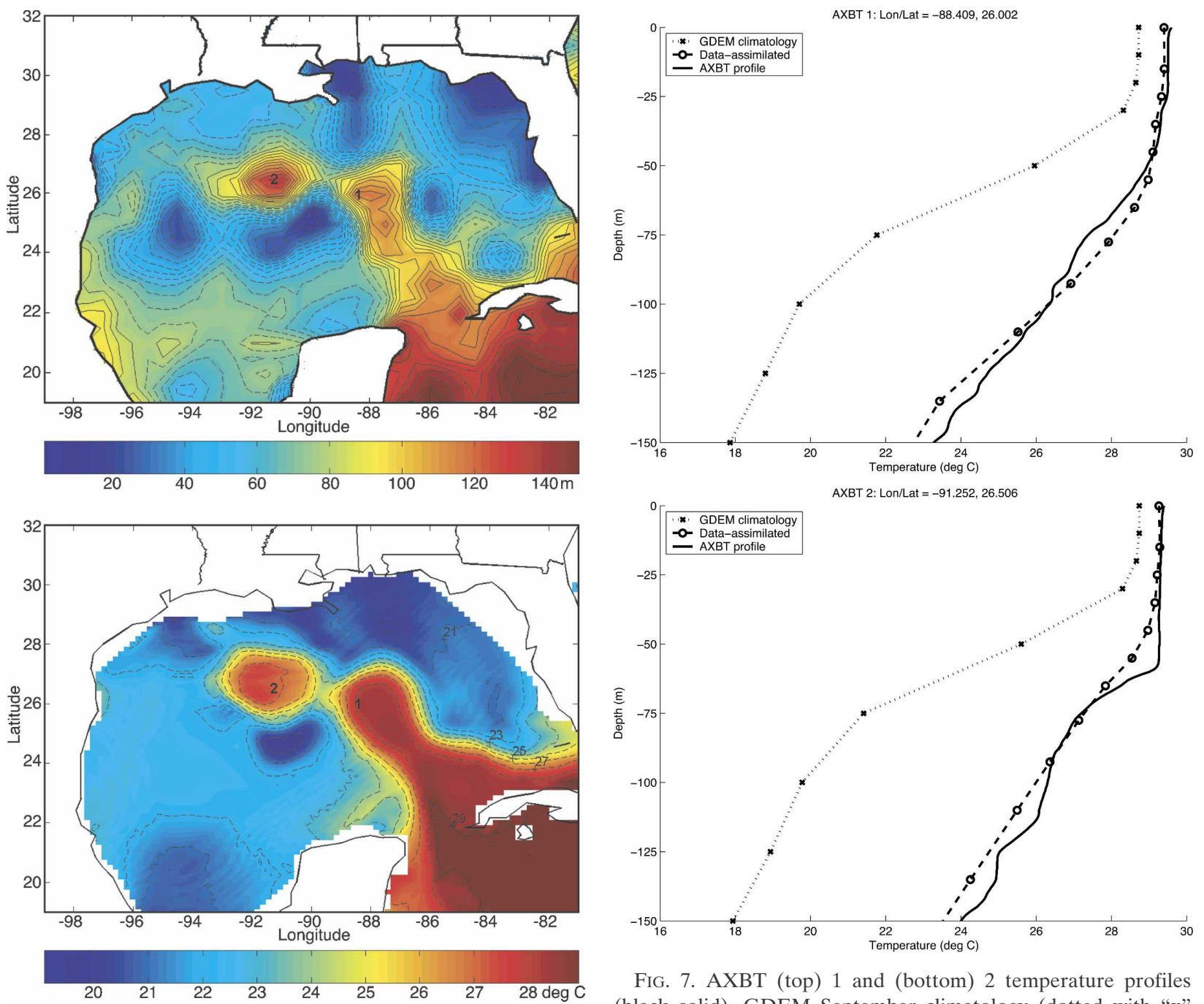

FIG. 7. AXBT (top) 1 and (bottom) 2 temperature profiles (black solid), GDEM September climatology (dotted with " $x$ " markers), and model profiles after the ocean model initialization (dashed with circle markers). AXBT positions are shown in the top labels and the position relative to the rest of the Gulf of Mexico basin is indicated in Fig. 6.

pared to the GFS, with easterlies in the GFDL extending unrealistically to nearly $400 \mathrm{hPa}$. As a result, the

Michelle (Fig. 8), which threatened the Florida Keys in early November 2001. This late-season storm was forecasted excellently by the GFS (called the AVN in 2001), which predicted that the storm would remain well south of Florida. The operational GFDL model performed very poorly because of problems with the initialization and failure of the model to represent properly the interaction of the storm with an approaching trough and cold front that moved into the Gulf of Mexico. The cross sections of the zonal component of the wind (Fig. 9) across the Gulf of Mexico, well north of the storm, showed that the westerlies in the upper levels were much weaker in the GFDL model comoperational GFDL model was unable to forecast correctly the more eastward track of Michelle, and instead predicted landfall of a major hurricane in southwest Florida. In addition, the filters designed to remove the vortex in the GFS global analysis retained part of the vortex, resulting in a distorted environmental field near the storm center (figure not shown). This resulted in a spurious westward motion during the first $12 \mathrm{~h}$ (Fig. 8). With the upgrades made to the model in 2002, the initial motion was improved. However, the model still forecasted the threat of a major hurricane landfall in south Florida. With the improvements to the model physics in 2003, the large-scale meridional winds fore- 


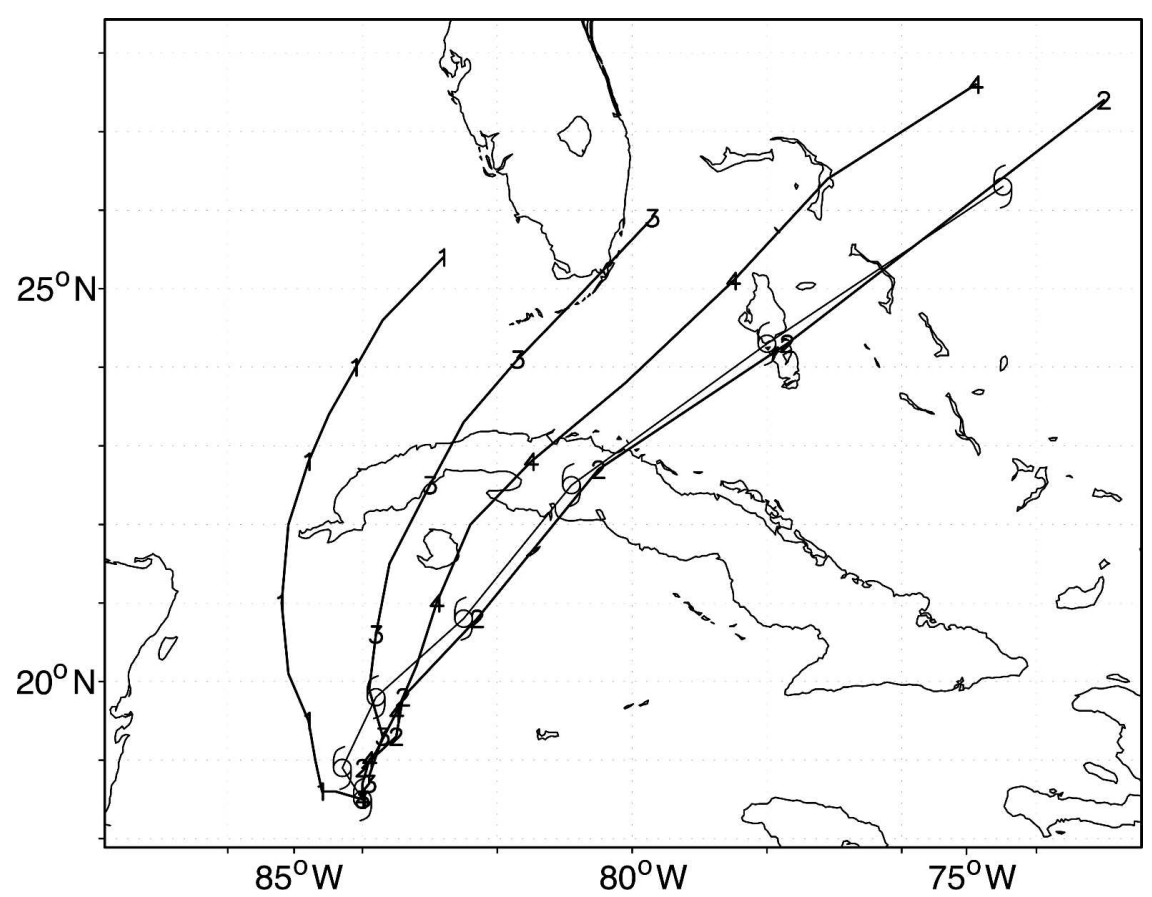

FIG. 8. The 72-h track forecasts of Hurricane Michelle (0000 UTC 3 Nov, initial time) for the 1) GFDL and 2) GFS models operational in 2001,3) the 2002 version of the GFDL model, and 4) the 2003 version of the GFDL model.

casted by the model were much closer to the GFS winds (figure not shown) and the forecasted track stayed south of Florida, with the model correctly forecasting the sharp turn to the right, greatly reducing the threat to Florida.

Since the major upgrades to the vertical resolution and the physics in 2003, the GFDL model has performed very well for track prediction in both the Atlantic (Fig. 10) and eastern Pacific (Fig. 11), providing the best overall track guidance in both basins. In the Atlantic, the interpolated version of the GFDL model guidance (GFDI; see Table 1 for explanation) exhibited skill relative to the Climatology and Persistence Model (CLIPER) of $40 \%, 51 \%, 47 \%, 41 \%$, and $35 \%$ at forecast days 1, 2, 3, 4, and 5 (Fig. 10). This is compared to the $37 \%, 48 \%, 44 \%, 39 \%$, and $36 \%$ skill relative to CLIPER for the GFS, which was the next best model. The very small track errors at 12 and $24 \mathrm{~h}$ represent a significant improvement over previous years, and were likely due to the changes to the model initialization as well as the upgrades to the model physics. In the eastern Pacific the skill relative to CLIPER ranged from $29 \%$ at 2 days to $6 \%$ at 5 days. Overall, in both basins, the upgraded GFDL system had the lowest track error of any other dynamical guidance available to TPC, except at day 5 . The degradation at $120 \mathrm{~h}$, particularly in the eastern Pacific, appears partly to be due to prema- ture recurvature in several storms (e.g., Hurricane Daniel during the 2006 season), resulting in a large northward and eastward bias at day 5 of 105 and 172 $\mathrm{nm}$, respectively. This bias was nearly 3 times larger than the average bias of the three global models, although the various global model biases did not favor any specific direction. For example, the GFS had eastward and southward biases at 5 days of 54 and $29 \mathrm{~nm}$, while the U.S. Navy Operational Global Atmospheric Prediction System (NOGAPS) had a westward and northward bias of 53 and $65 \mathrm{~nm}$. In the Atlantic, the GFDL model also exhibited a north bias at 5 days of $137 \mathrm{~nm}$, with a small east bias of $47 \mathrm{~nm}$.

The track errors in the Atlantic during the past four hurricane seasons were the smallest ever for the GFDL model since it became operational in 1995 (Fig. 1). It is quite encouraging that, except for the 2001 hurricane season in which the GFDL did not perform well (in part due to problems already discussed with the vortex removal algorithms), the overall trend of both the GFDL and GFS models shows steady improvement in track performance over the past $10 \mathrm{yr}$. The GFDL model provided reliable track forecast guidance to TPC for the most devastating hurricane in U.S. history, Hurricane Katrina. While an east bias existed in the early forecasts of Katrina before landfall in Florida (e.g., Fig. 21), all of the GFDL forecasts starting on or after 1200 


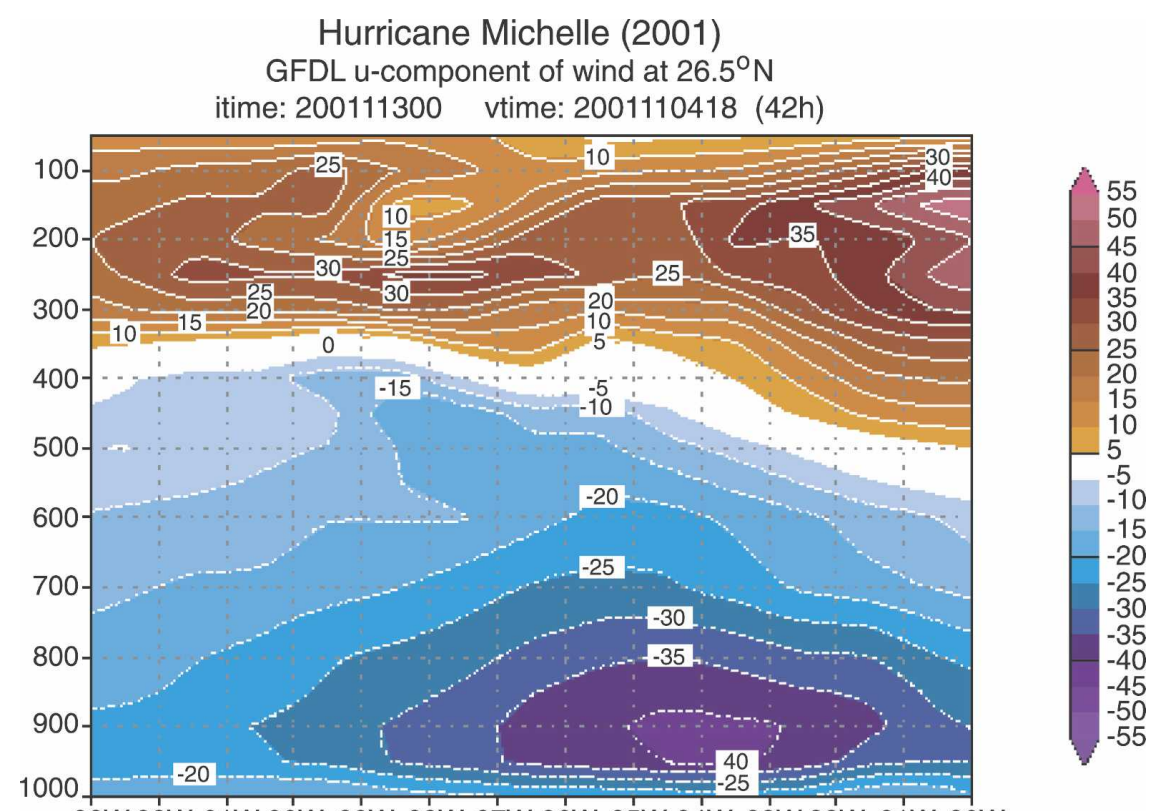

Hurricane Michelle (2001)

AVN u-component of wind at $26.5^{\circ} \mathrm{N}$

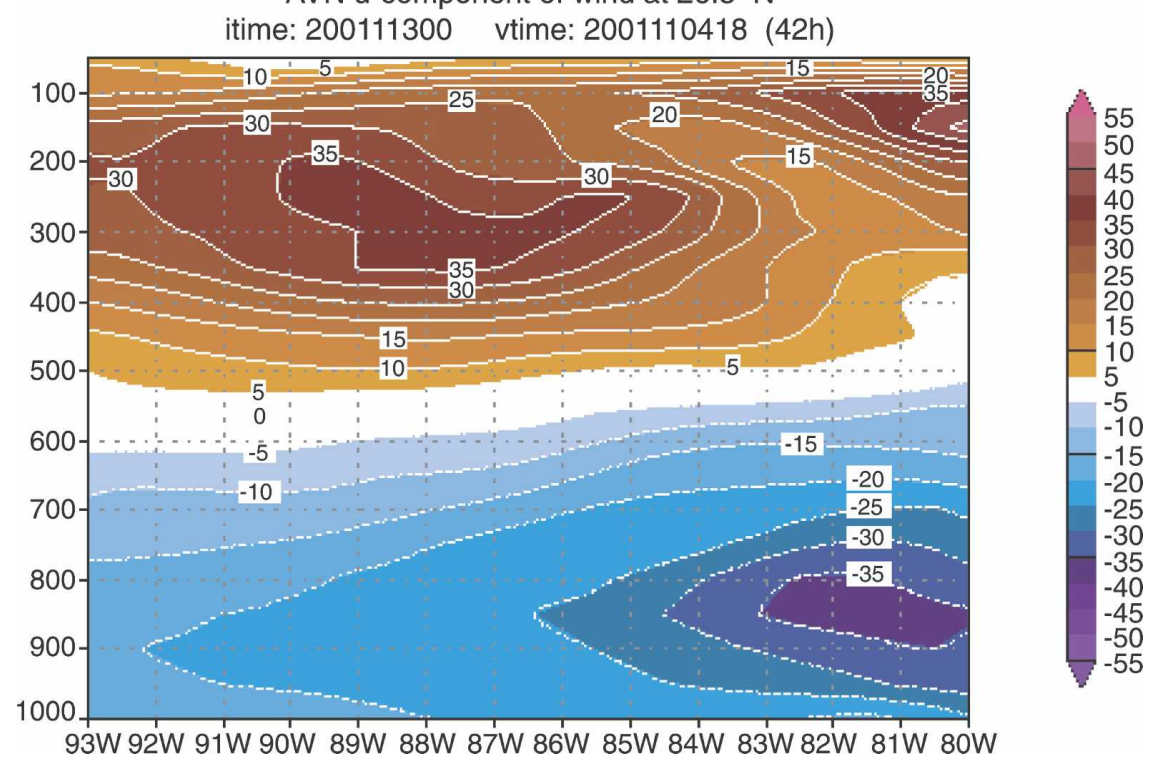

FIG. 9. Vertical cross sections across the Gulf of Mexico $\left(26.5^{\circ} \mathrm{N}\right)$ at forecast hour 42 from the 0000 UTC 3 Nov forecast of Hurricane Michelle for the operational (top) GFDL model and (bottom) GFS model. The $u$ component of the wind is plotted $\left(\mathrm{m} \mathrm{s}^{-1}\right)$.

UTC 26 August predicted landfall on or near the eastern Louisiana coastline (Fig. 12).

Concerning intensity prediction, the large positive bias of the GFDL model was reduced with the physics upgrades introduced in 2003. For example, over the past $4 \mathrm{yr}$ the average intensity bias of the GFDL and GFDI model guidance in the Atlantic basin were only about -0.2 and $-2.5 \mathrm{kt}$ averaged over all of the time periods. This compares to a positive bias (overprediction of intensity) of 15 and $13 \mathrm{kt}$ in 2002 for the GFDL and GFDI models.

Figure 13 shows the trend in the errors of the 48- and 72-h forecasts of maximum winds during the past 200006 Atlantic seasons for the GFDL, GFDI, and the Statistical Hurricane Intensity Prediction System with the land effect included (Decay SHIPS). Prior to 2006, 


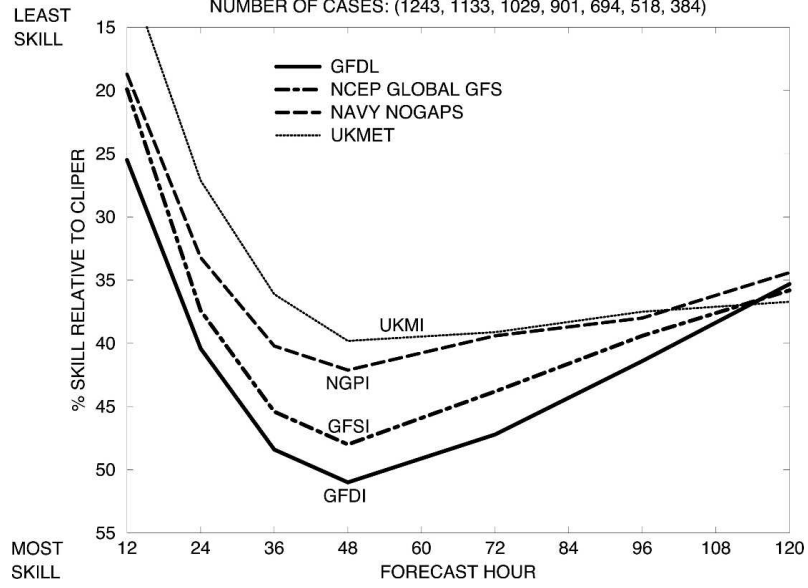

FIG. 10. Summary of the combined 2003, 2004, 2005, and 2006 Atlantic hurricane season track skill plotted relative to CLIPER, for the time-interpolated GFDL model (GFDI; solid line), compared to NCEP's interpolated GFS model (dot-dashed line), the U.S. Navy's interpolated NOGAPS global model (NGPI; dashed line), and the interpolated Met Office global model (UKMI; dotted line). (See Table 1 for a detailed explanation of the method used to compute the time-interpolated models.)

the Decay SHIPS has had the lowest intensity errors of any model during this period. However, the intensity errors for the GFDI model guidance showed significant reduction after the major physics upgrades were introduced in 2003 and 2006. For example, in the 3-yr period prior to the upgrade with NCEP physics in 2003, the GFDI 48- and 72-h intensity errors averaged 20.1 and $24.6 \mathrm{kt}$, respectively, with 16 - and 20.8-kt errors, respectively, for Decay SHIPS. In the next 3-yr period (200305 ) after the 2003 physics upgrade, the GFDI wind errors decreased to about $15 \%$ with 48 - and 72 -haveraged intensity errors of 17.2 and $21.0 \mathrm{kt}$. However, Decay SHIPS still significantly outperformed GFDI,

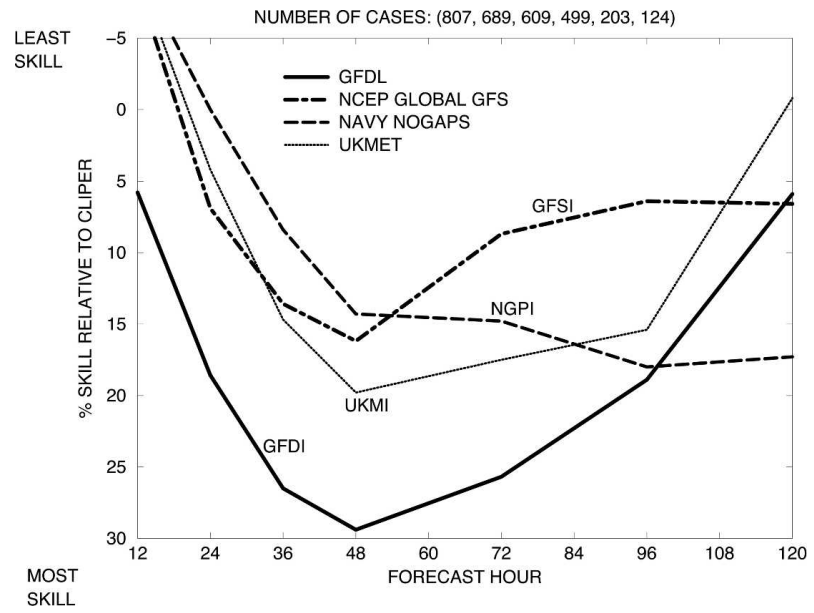

FIG. 11. Same as Fig. 10, but for the eastern Pacific basin.

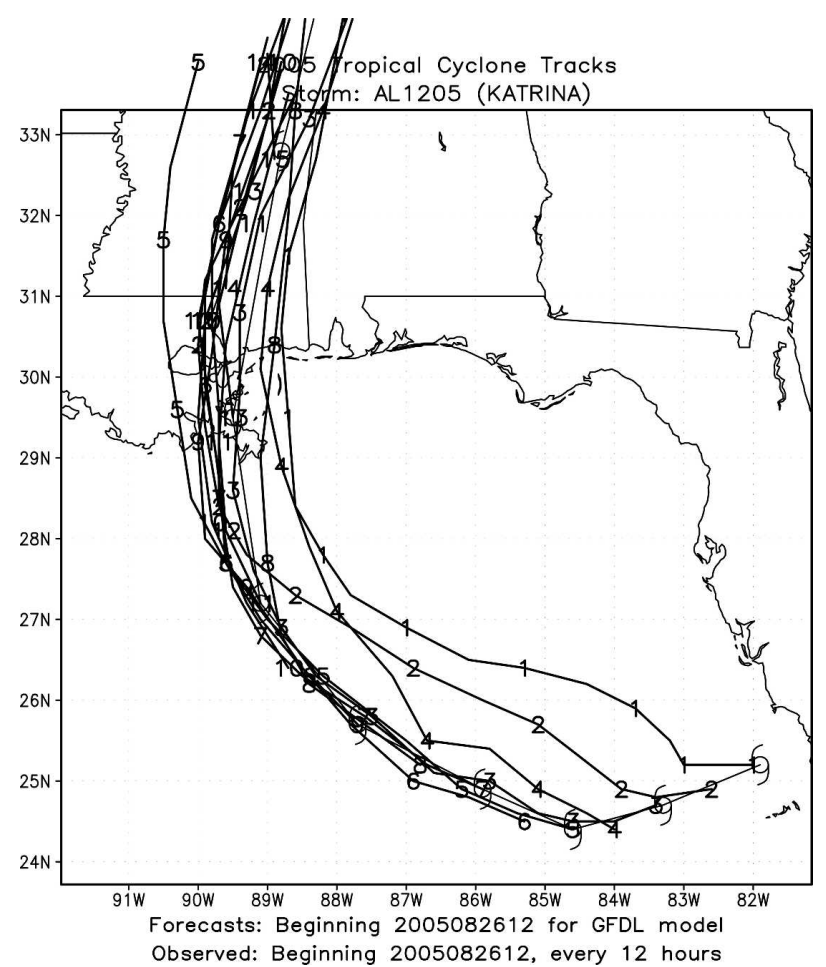

FIG. 12. Composite of all GFDL forecasts for Hurricane Katrina, starting on or after 1200 UTC 26 Aug. The observed track is noted by the black line with the observed position at $12-\mathrm{h}$ intervals denoted by the hurricane symbol.

with errors of 14.8 and $18.8 \mathrm{kt}$ at these two time levels. After implementation of the 2006 upgrade, the GFDI wind error at 48 and $72 \mathrm{~h}$ decreased to 12.7 and $14.7 \mathrm{kt}$, compared to 16 and $21 \mathrm{kt}$ for Decay SHIPS. This is the first year that GFDI clearly outperformed Decay SHIPS at every forecast time level beyond $12 \mathrm{~h}$. Although this large improvement in the performance of the GFDL model after the 2006 physics upgrades was evaluated over only one season, a similar tendency for much-reduced intensity error was found when the 2006 GFDL model was extensively tested on storms during the 2004 and 2005 seasons (discussed below). It should also be noted that the performance of Decay SHIPS in 2006 was similar to its performance during the previous $6 \mathrm{yr}$ (e.g., 15.2 and $19.6 \mathrm{kt}$, respectively, at 48 and $72 \mathrm{~h}$ ). At the same time, the overall reduction in the GFDI errors in 2006 was nearly $33 \%$, compared to its performance over the past $6 \mathrm{yr}$, which further suggests that the two major physics upgrades in 2006 have resulted in very significant improvements in the reliability of the model for intensity prediction.

In the eastern Pacific the GFDI model outperformed the statistical intensity models at only 96 and $120 \mathrm{~h}$, because the GFDI model tended to underpredict many of the intense hurricanes during the 2006 season. This 

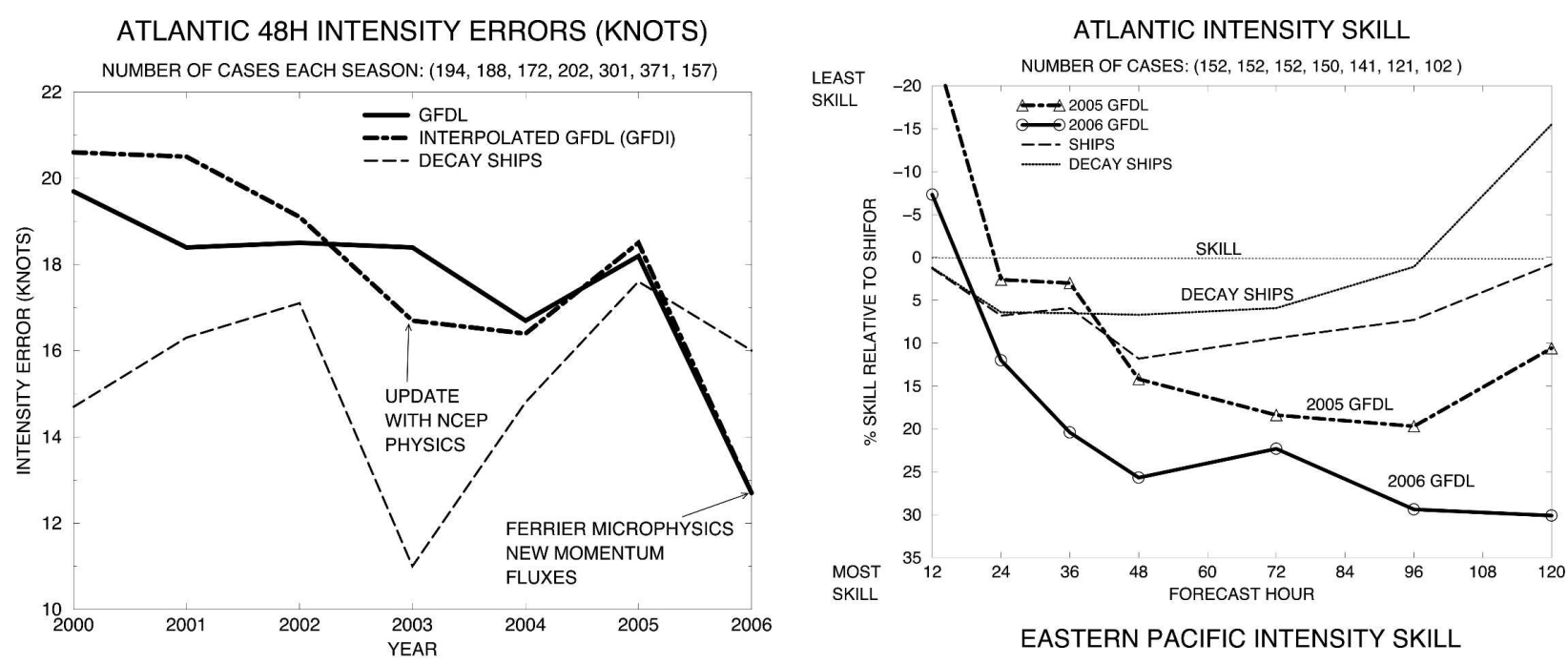

ATLANTIC 72H INTENSITY ERRORS (KNOTS)

NUMBER OF CASES EACH SEASON: $(158,143,143,148,255,289,123)$
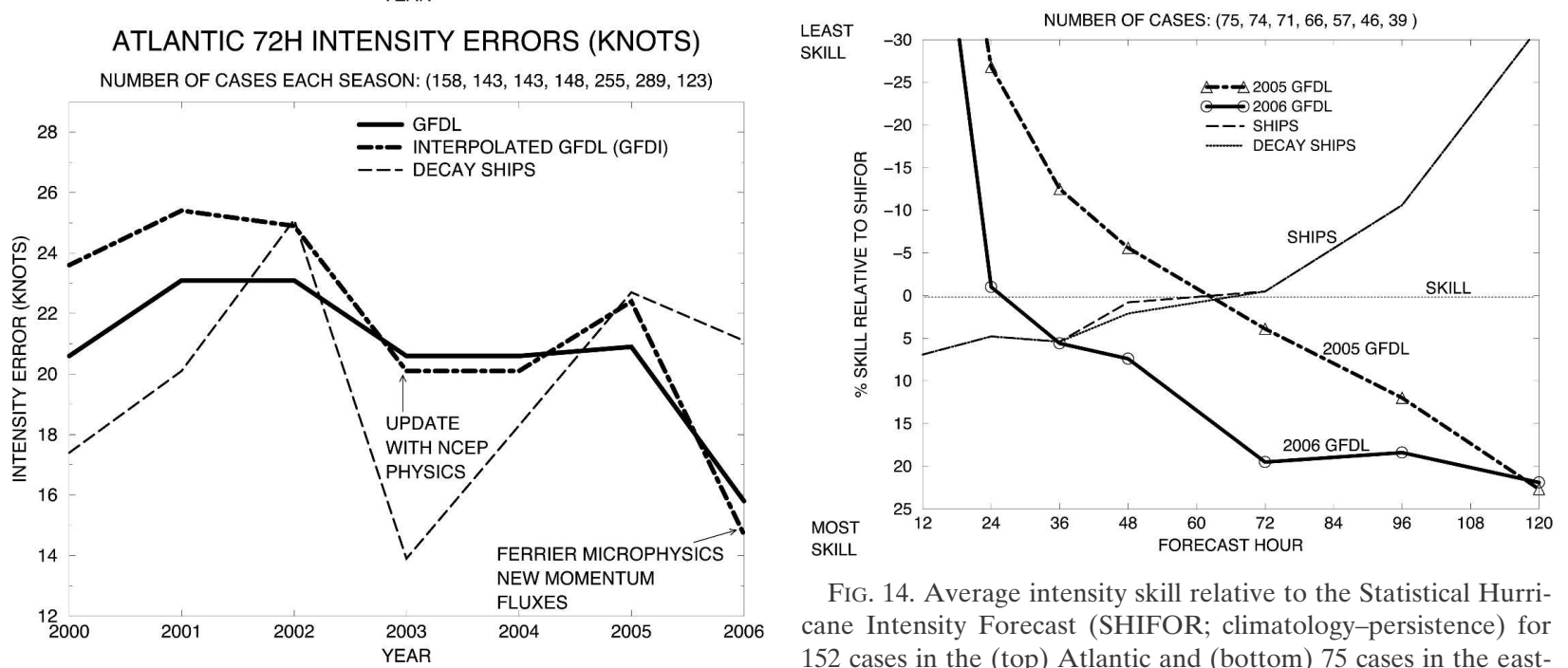

FIG. 14. Average intensity skill relative to the Statistical Hurricane Intensity Forecast (SHIFOR; climatology-persistence) for 152 cases in the (top) Atlantic and (bottom) 75 cases in the eastern Pacific run with the new upgraded GFDL model made operational in 2006 (solid line, circle), compared to forecasts run with the 2005 version of the model (dot-dashed, triangle) and the statistical models with (Decay SHIPS) and without (SHIPS) the effect of land included. The version of the GFDL model shown is not the time-interpolated forecast versions.

resulted in a negative intensity bias of about $4 \mathrm{kt}$ in the 24-72-h period and 6-10 kt in the 96- and 120 -h periods. It should be noted the actual GFDL model, without the correction for the initial wind error, showed considerably more skill then the GFDI model in the eastern Pacific with significantly reduced negative bias.

\section{b. Performance of GFDL system with 2006 upgrades}

As previously stated, major upgrades to both the atmospheric and ocean components of the GFDL model were made operational in the 2006. To evaluate the performance of the new package, forecasts were compared with the 2005 and 2006 versions on a sample size

of 153 forecasts using cases from the extremely active 2004 and 2005 Atlantic hurricane seasons, and 75 forecasts from the 2005 eastern Pacific season. The cases selected involved both intense storms as well as weaker storms, such as Lisa (2004) and Philippe (2005), in which the previous version of the GFDL model had a large positive intensity bias. In this section, a summary of the improvements in both the intensity and track prediction is presented. It will be shown that the new model not only better predicts the intensification of the stronger storms, but also greatly reduces the positive bias in weaker storms that are undergoing significant vertical shear. 

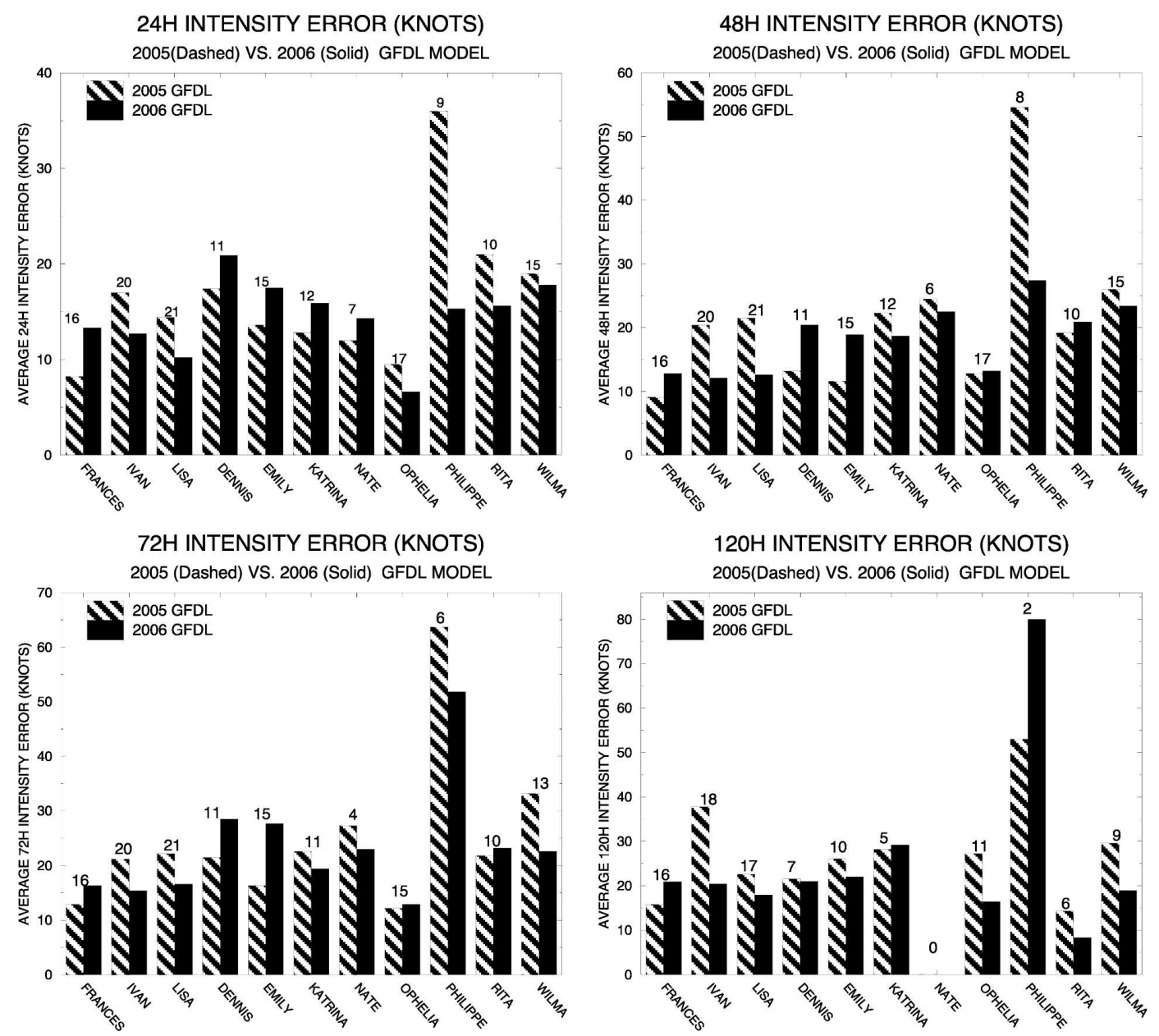

FIG. 15. Distribution by storm of the average intensity error (kt) at 24, 48, 72, and $120 \mathrm{~h}$ for the forecasts run with the 2005 version of the GFDL model and the version made operational in 2006. Cases selected were from the 2004 and 2005 Atlantic hurricane season. Total number of forecasts run for each storm is indicated by the number above each histogram.

Figure 14 compares the intensity errors for both the 2005 and 2006 versions of the GFDL system for the 152 and 75 case sample sizes in the Atlantic and eastern Pacific basins. (The sample size in the Atlantic was reduced by one in this homogenous comparison due to the unavailability of one SHIPS forecast.) For all of the model comparisons in this subsection the actual GFDL model is evaluated, not the interpolated version (GFDI). The comparison with the statistical models in Fig. 14 is not meant to be a strict comparison between the skill of the GFDL model and the statistical models to which the TPC forecasters had access, but to give an overall comparison of the percent of improved performance found with the upgraded system compared to these models' performance. It is encouraging that the 2006 GFDL forecast system is showing considerably improved skill at most time levels compared to the previous version. Note that at forecast days 4 and 5 in the
Atlantic, while the 2005 GFDL skill began to level off, the new model continued to exhibit greater skill. The greatest number of improved forecasts at the longer time period involved the most intense storms, where the negative bias (underprediction of intensity) was reduced. For the entire sample size in the Atlantic the bias was reduced from $-4,-7$, and -11 to $-0.3,2$, and $3 \mathrm{kt}$ at forecast days 3,4 , and 5 , and from $-3,-6.5$, and -8.6 to $-2.5,-2$, and -2.5 in the eastern Pacific. At forecast days 2-5 the average error in the Atlantic was reduced by $13 \%, 5 \%, 12 \%$, and $22 \%$, respectively, with the actual error reduced by 2.6, 1.0, 2.8, and $5.6 \mathrm{kt}$.

A comparison of the intensity errors for each of the 11 storms tested in the Atlantic (Fig. 15) indicates that the storm with the largest reduction of average error was Hurricane Philippe. The 2005 GFDL quickly intensified this storm to a category- 4 hurricane by 2 days, resulting in enormous intensity errors of $55 \mathrm{kt}$ by $48 \mathrm{~h}$. 


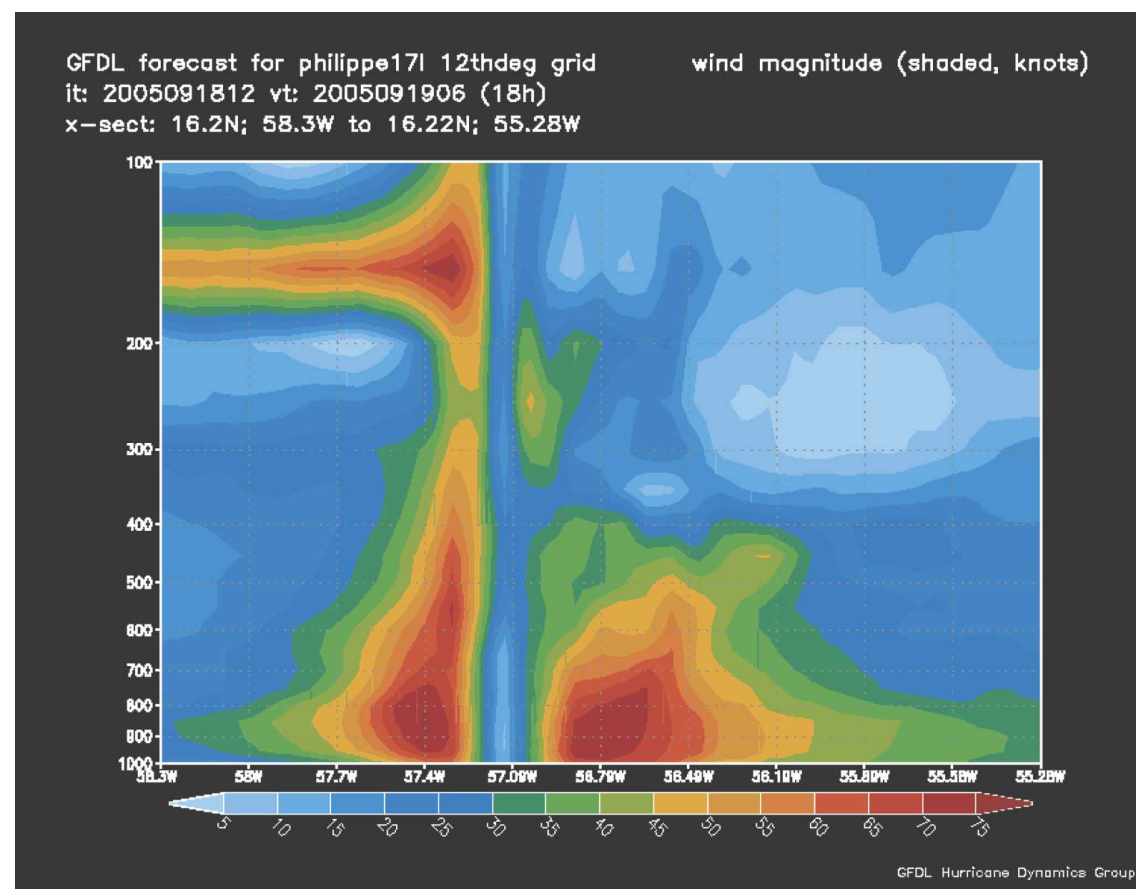

GFDL forecast for 26Uphilippe17l 12thdeg grid wind magnitude (shaded, knots)

it: 2005091812 vt: $2005091906(18 \mathrm{~h})$

$x-$ sect: $15.87 \mathrm{~N} ; 58.3 \mathrm{~W}$ to $16.2 \mathrm{~N} ; 55.38 \mathrm{~W}$

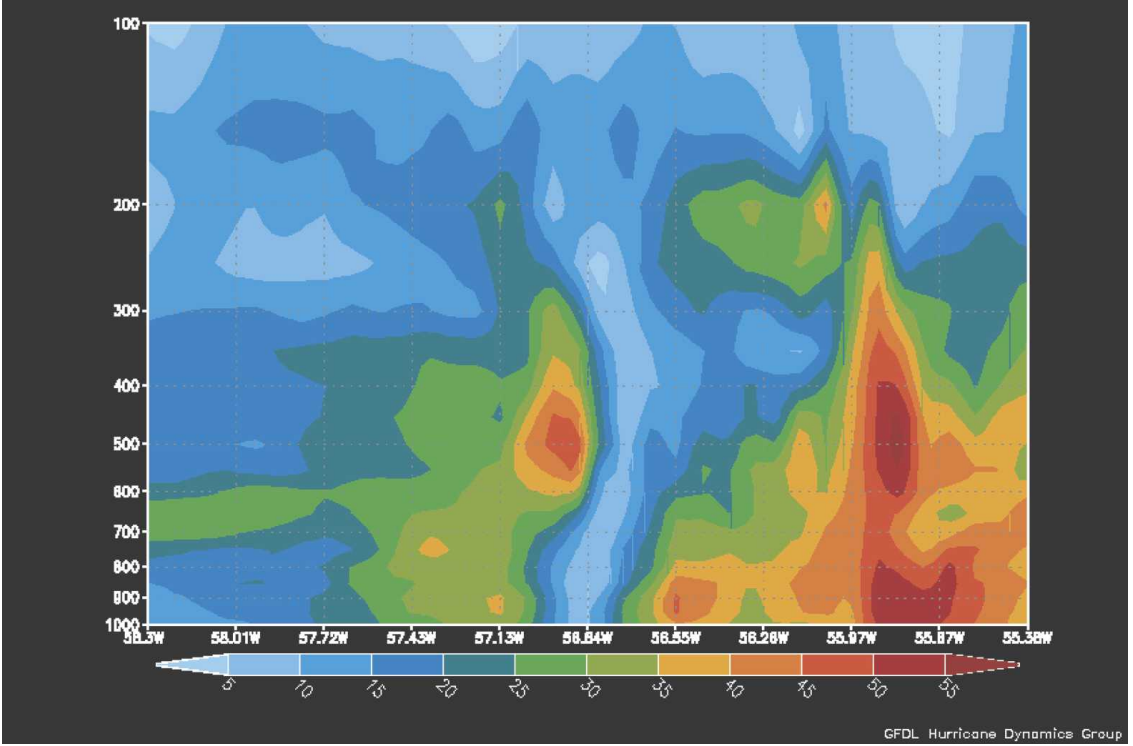

FIG. 16. Cross section of total wind speed through the storm center of Hurricane Philippe (2005) at forecast hour 18, for the forecast beginning at 1200 UTC 18 Sep, with the 2005 version of the (top) GFDL model and (bottom) the new 2006 version.

The actual storm briefly gained hurricane status on 19 and 20 September as a minimal 65-70-kt hurricane before being sheared by an upper-level low to the northwest of the storm (Franklin 2006). Despite the presence of strong southwesterly shear over the system, the inner core remained vertically coherent in the old model (Fig.
16, top), compared to the storm from the model with the upgraded physics (Fig. 16, bottom), which quickly became tilted due to the influence of the upper-level westerly winds. With the strong upper-level winds advecting the ice condensate away from the storm center, the heavy precipitation became well displaced to the 
east (figure not shown), which also agreed with observations (R. Pasch 2006, personal communication). It is interesting to note that after $48 \mathrm{~h}$ even the 2006 GFDL model began to intensify Philippe rapidly, as the upperlevel westerly winds in the model incorrectly lifted north of the storm, producing a very favorable environment for strengthening.

The two other storms that had the largest reduction in intensity errors were Lisa (2004), which was also a weak, sheared system that was overintensified by the original GFDL model, and Ivan (2004), which was an intense category-5 hurricane. The upgraded GFDL system did a better job of handling the intensity of Lisa and the rapid intensification of Ivan. The average 48-, 72-, and 120-h intensity errors for Hurricane Ivan were 12,15 , and $20 \mathrm{kt}$ compared to 20,26 , and $38 \mathrm{kt}$ with the 2005 version of the GFDL model. The worst degraded performance with the new model was with the early season storms, Hurricanes Dennis (2005) and Emily (2005), because the new model failed to capture the rapid intensification, although the forecasts at day 5 slightly improved. For the remaining category- 4 and -5 storms the results were mixed, with a reduction of error for Hurricanes Katrina (2005) and Wilma (2005) and increased error for Hurricane Frances (2004). Intensity errors for Hurricane Katrina were reduced by about 4 $\mathrm{kt}$ at 2 and 3 days. The impact of the improved representation of the Loop Current in the ocean model for this storm was particularly important for the intensity improvements. Figure 17 shows an example of the improved intensity forecast with the new initialization of the Loop Current. This figure compares two forecasts initiated on 1200 UTC 26 August with the 2006 model physics, but using the old and new Loop Current initialization procedures. In the old procedure, the Loop Current was initialized from the GDEM monthly climatology, while in the new procedure the real-time satellite altimeter data are used. With the proper initialization of the Loop Current position and structure, the model correctly predicted the rapid intensification of Katrina over the Loop Current, as noted in the central pressure. While the tendency was forecasted correctly, the GFDL model still underpredicted Katrina's peak intensity, probably due to insufficient horizontal resolution in the inner core.

Two other examples of intensity forecasts for Hurricane Katrina (0000 UTC 24 August and 1200 UTC 24 August) that are shown in Fig. 18 demonstrate the much-improved reliability of the new modeling system. In the first example (top), when the storm was still at depression strength, the storm was forecasted by the 2005 model version to remain a depression. The new model forecasted steady intensification throughout the
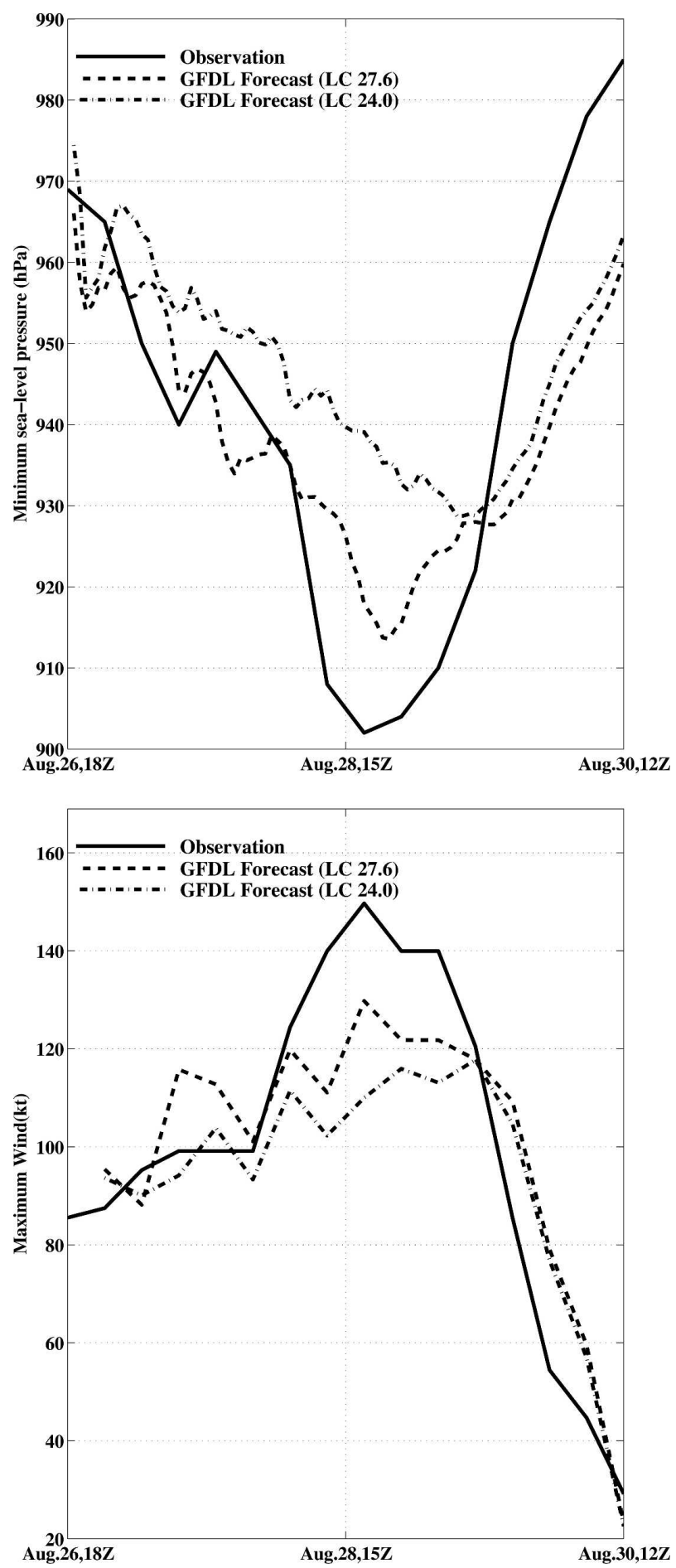

FIG. 17. Forecasts of (top) central pressure and (bottom) maximum wind speed with the 2006 GFDL system of Hurricane Katrina for the initial time of 1200 UTC 26 Aug, with the old (dotdashed) and new (dashed) initialization of the Loop Current in the Gulf of Mexico. Black lines show the observed central pressure and maximum wind speed. 

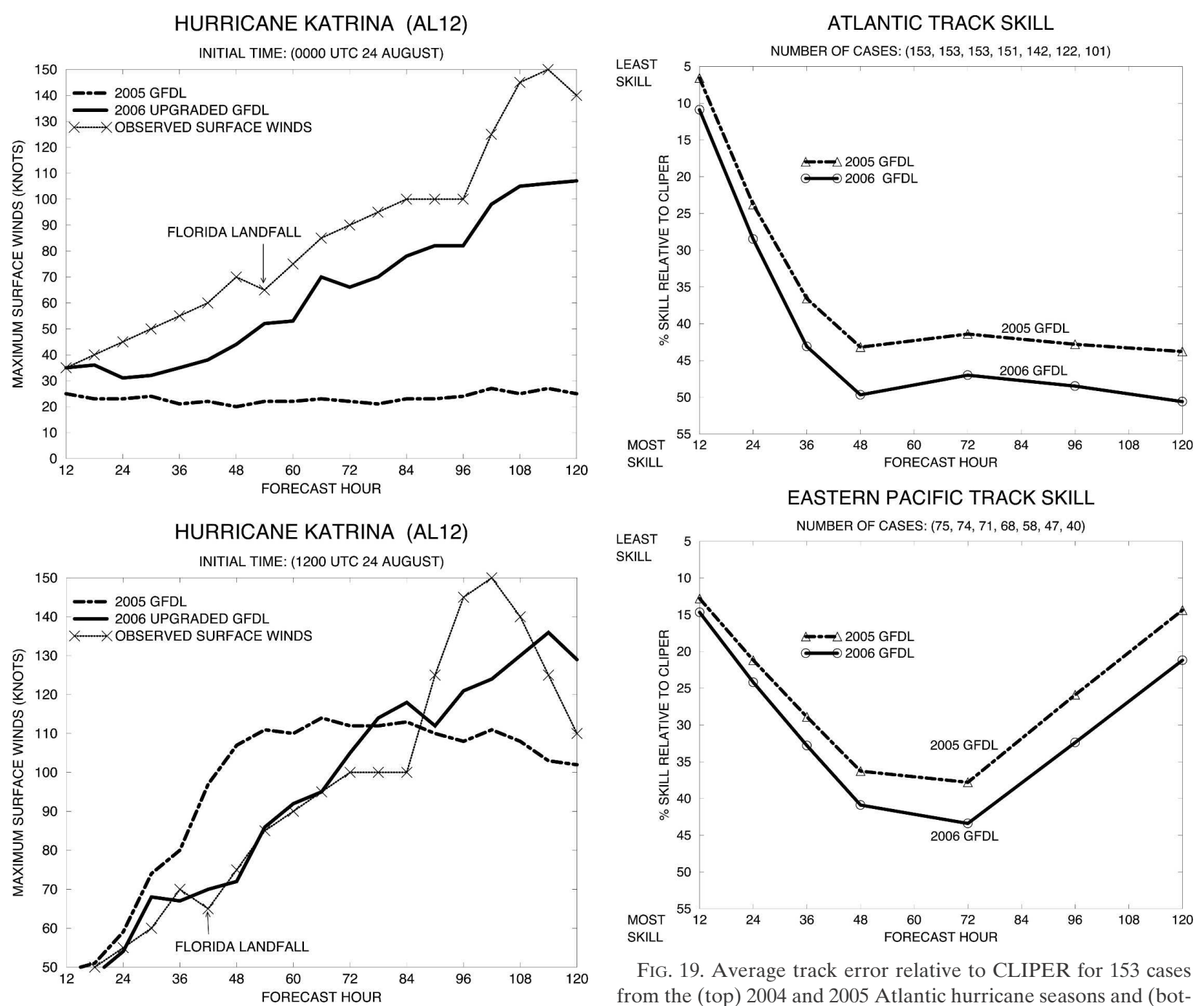

FIG. 19. Average track error relative to CLIPER for 153 cases

FIG. 18. Time series of maximum 10-m winds for two cases of Hurricane Katrina with the 2005 operational version of the GFDL model (dot-dashed line), the new 2006 GFDL (solid line), and the observed surface winds (dotted line, $\mathrm{X}$ ).

5-day period, with the storm becoming a strong category-3 hurricane as it approached the northern Gulf. Twelve hours later, when the storm was still well east of Florida (Fig. 18, bottom), the 2005 system forecasted rapid strengthening almost immediately, despite the presence of northerly shear (not shown), and the model storm became a borderline category-3 hurricane as it passed just south of Florida. In contrast, with the new physics, the storm intensity was forecasted much better, with gradual strengthening to $72 \mathrm{kt}$ during the first 2 days. Both systems still failed to predict the rapid intensification between 84 and $102 \mathrm{~h}$, although the new model still predicted that Hurricane Katrina would be a strong category-4 hurricane as it approached the northern Gulf Coast by the end of the period.

from the (top) 2004 and 2005 Atlantic hurricane seasons and (bottom) 75 cases from the 2005 eastern Pacific hurricane season, comparing forecasts using the 2005 and 2006 versions of the GFDL hurricane forecast system.

Finally, the average track improvement with the 2006 model was evaluated for both the Atlantic and eastern Pacific. The new modeling system exhibited reduced track error at all time levels in both of basins (Fig. 19). The results were statistically significant at the $96 \%$ level for lead times of 36 through $120 \mathrm{~h}$ in the Atlantic, with an average reduction in error of about $11 \%$. The frequency of superior performance during these time periods averaged $62 \%$ for the new modeling system in the Atlantic. In the eastern Pacific the average reduction in error was $7 \%$, with an average frequency of superior performance of $60 \%$ over the 2005 GFDL model. However, the improvements were only statistically significant at the $95 \%$ level at 3 days.

The distribution of the 2-, 3-, 4-, and 5-day track error for the 11 storms tested (Fig. 20) indicates that with the 

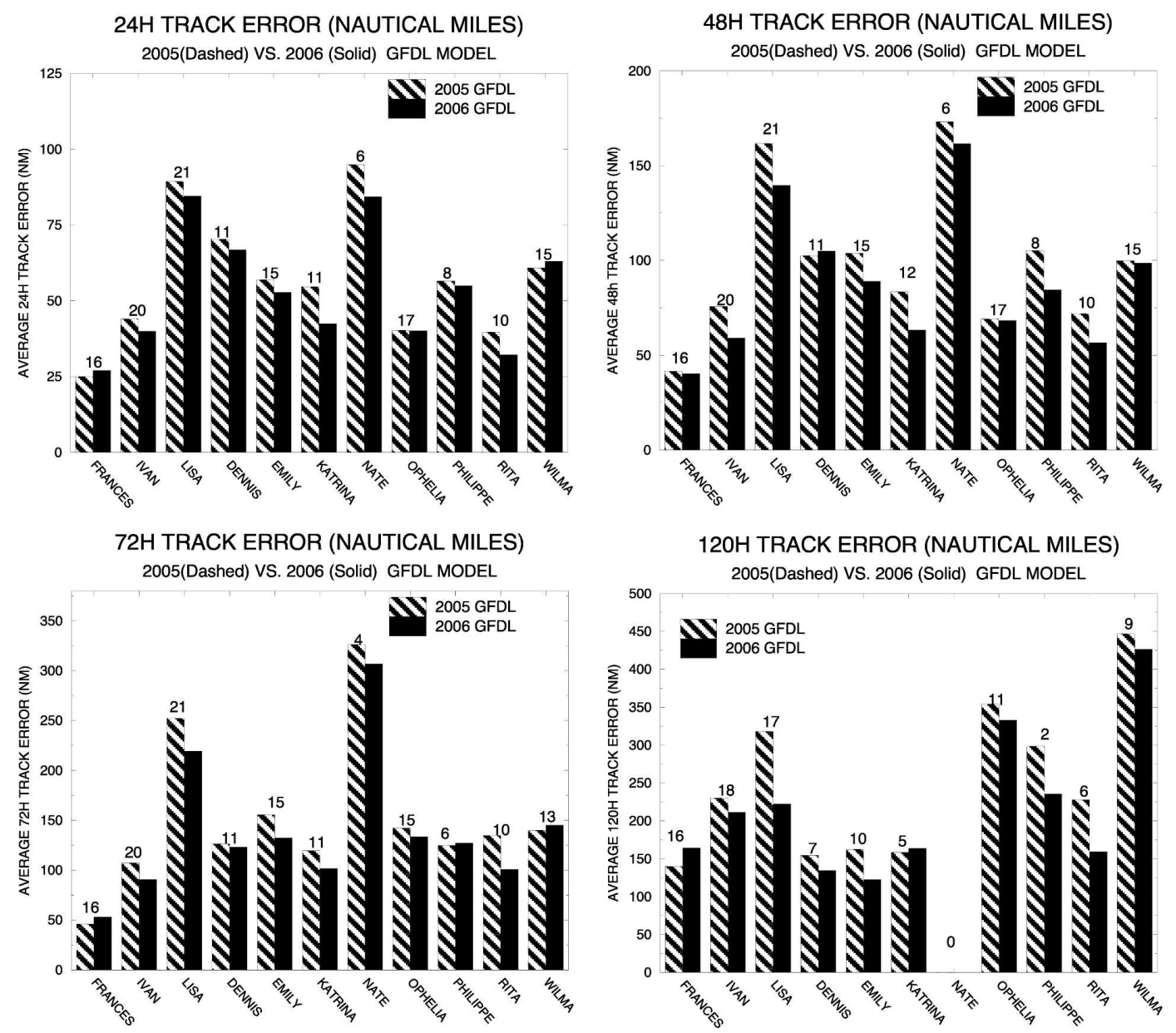

FIG. 20. Distribution by storm of the average track error at $24,48,72$, and $120 \mathrm{~h}$ for the forecasts run with the 2005 version of the GFDL model and the version made operational in 2006. Cases selected were from the 2004 and 2005 hurricane season. Total number of forecasts run for each storm is indicated.

exception of Hurricane Frances most of the storms showed some improved track forecast performance, particularly Hurricanes Lisa and Rita. Although the new model failed to predict the landfall of Hurricane Katrina on the Louisiana coastline for forecasts initialized when the hurricane was east of Florida (Fig. 21), most of the tracks exhibited a reduced eastward bias, and the overall track error was reduced, except at $120 \mathrm{~h}$. For Hurricane Rita, the reduced track error was primarily due to a reduction of the west bias that most of the prediction models continued to exhibit as the hurricane approached the Texas-Louisiana coastline (figure not shown).

\section{Concluding comments}

This paper has summarized the improvements made to the GFDL hurricane forecast system during the past decade and evaluated the performance of the GFDL model guidance as an operational forecast product.
These improvements have resulted in a continued decrease in the model's track forecast error, with the lowest overall track errors of any dynamical model guidance available to the NWS Tropical Prediction Center in both the Atlantic and eastern Pacific basins during the past 4 yr. In addition, since major upgrades were made to the model physics and vertical resolution in 2003 , the model has begun to demonstrate improvement in intensity prediction. In 2006 the interpolated GFDL model guidance (GFDI) outperformed the statistical intensity prediction models at all time levels beyond $12 \mathrm{~h}$ in the Atlantic and at 96 and $120 \mathrm{~h}$ in the eastern Pacific. This is the first season that GFDI showed superior performance compared to the statistical forecast models. In the Atlantic, the GFDI wind errors were reduced by $30 \%$ compared to the previous 3-yr mean error. The 2006 GFDL model also demonstrated significantly reduced intensity error compared to the 2005 version when extensive reruns were made 
Hurricane Katrina
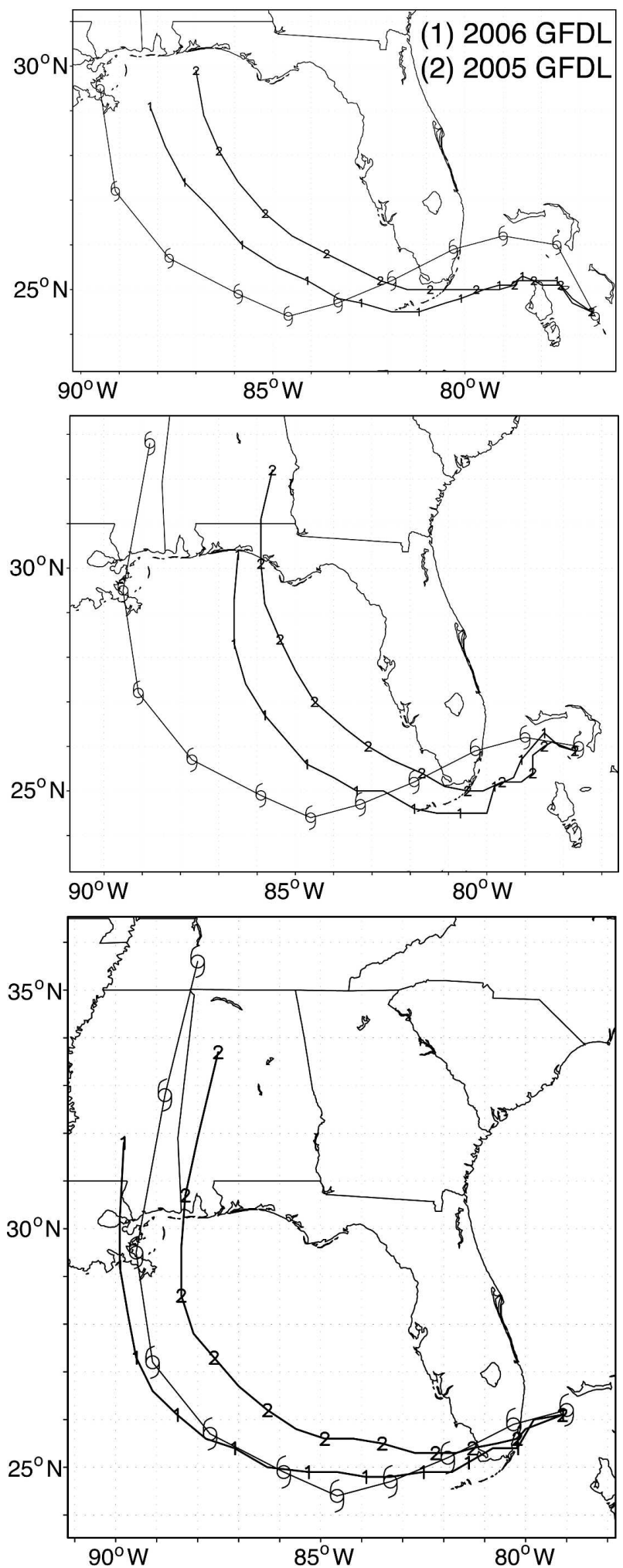

FIG. 21. Comparison of the hurricane track for three forecasts of Hurricane Katrina with the 2) 2005 operational GFDL model and 1) the new 2006 system. Forecasts are initialized at (top) 1200 UTC 24 Aug, (middle) 0000 UTC 25 Aug, and (bottom) 1200 UTC 25 Aug. on forecasts during the two very active Atlantic hurricane seasons of 2004 and 2005 and a smaller set of cases from the 2005 eastern Pacific season. These two results indicate that the major physics upgrades introduced in the 2006 version (e.g., implementation of microphysics and an improved surface momentum flux parameterization) are essential to significantly improve the reliability of intensity prediction with the GFDL model.

The initial implementation of the new nonhydrostatic Hurricane WRF (HWRF) will utilize most of the physics packages that are operational in the 2006 version of the GFDL system. For this reason, the paper detailed these latest physics upgrades and the significant reduction in track $(\sim 11 \%)$ and intensity $(\sim 13 \%)$ error that was found when this extensive set of forecasts using the 2006 GFDL model were compared with the 2005 version. These cases were selected to include both intense storms and the weaker sheared systems that the previous versions of the GFDL model forecasted poorly. Because the new 2006 model demonstrated improved track and intensity forecasts in both types of storms, this gives confidence that the HWRF will continue the trend of reduced track and intensity errors that has been shown with the GFDL model over the previous $6 \mathrm{yr}$.

During the past $11 \mathrm{yr}$, the GFDL hurricane forecast system has provided reliable operational forecast guidance both to forecasters at NOAA's Tropical Prediction Center and the Navy's Joint Typhoon Warning Center (JTWC). A critical aspect of its success was the multiyear effort to improve and transform a hurricane model that was originally developed for basic research into a highly successful operational product. This required commitment, encouragement, and vision on the part of management at GFDL and the National Weather Service. A second aspect that made this effort so successful was the collaboration between scientists at NOAA's GFDL laboratory, the Environmental Modeling Center at the National Weather Service's National Centers for Environmental Prediction, the Tropical Prediction Center, and scientists at the University of Rhode Island's Graduate School of Oceanography. Those that have been involved in this effort hope that its success will serve as an example of the potential advancements that can be achieved with collaboration between various government agencies and the academic community.

Acknowledgments. The authors wish to thank the Joint Hurricane Testbed under the auspices of the U.S. Weather Research Program for providing support that made the latest upgrades to the GFDL model possible. We are grateful to former GFDL directors, the late Joseph Smagorinsky, Jerry Mahlman, and Ants Leetma 
for their continued support of the hurricane project at GFDL over the past $30 \mathrm{yr}$, and to Stephen Lord and Naomi Surgi of NCEP for their support and encouragement, which has made this outstanding collaboration possible. Special thanks go to Hua-Lu Pan, Brad Ferrier, Aleksandr Falkovich, Tetsu Hara, Il Ju Moon, and Richard Yablonsky for their contribution to the improvement of the GFDL model physics. Special thanks go to Christopher Kerr of the University Corporation for Atmospheric Research for his invaluable assistance through the years to improve the model's computational efficiency for operations. We are grateful to TPC personnel James Franklin and Michelle Mainelli for providing data and to James Gross, James Franklin, and Richard Pasch for their many discussions and insights that have contributed to the GFDL system improvements during the past decade. The authors are greatly indebted to Yoshio Kurihara who passed away in 2007 and was the founder of the hurricane project at GFDL and its leader until retirement in 1998.

\section{REFERENCES}

Arakawa, A., and W. H. Schubert, 1974: Interaction of a cumulus cloud ensemble with the large-scale environment, Part I. $J$. Atmos. Sci., 31, 674-704.

Bender, M. A., and I. Ginis, 2000: Real-case simulations of hurricane-ocean interaction using a high-resolution coupled model: Effects on hurricane intensity. Mon. Wea. Rev., 128, 917-946.

_, R. E. Tuleya, and Y. Kurihara, 1987: A numerical study of the effect of island terrain on tropical cyclones. Mon. Wea. Rev., 115, 130-155.

_ - I. Ginis, and Y. Kurihara, 1993: Numerical simulations of tropical cyclone-ocean interaction with a high-resolution coupled model. J. Geophys. Res, 98, 23 245-23 263.

Bister, M., and K. A. Emanuel, 1998: Dissipative heating and hurricane intensity. Meteor. Atmos. Phys., 65, 233-240.

Black, P. G., and Coauthors, 2007: Air-sea exchange in hurricanes: Synthesis of observations from the Coupled Boundary Layer Air-Sea Transfer Experiment. Bull. Amer. Meteor. Soc., 88, 357-374.

Blumberg, A. F., and G. L. Mellor, 1987: A description of a threedimensional coastal ocean circulation model. ThreeDimensional Coastal Ocean Models, N. Heaps, Ed., Amer. Geophys. Union, 1-16.

Boyer, T. P., and S. Levitus, 1997: Objective Analysis of Temperature and Salinity for the World Ocean on a 1/4 Degree Grid. NOAA Atlas NESDIS 11, 62 pp.

Cornillon, P., and R. Watts, 1987: Satellite thermal infrared and inverted echo sounder determinations of the Gulf Stream northern edge. J. Atmos. Oceanic Technol., 4, 712-723.

DeCosmo, J., K. B. Katsaros, S. D. Smith, R. J. Anderson, W. A. Oost, K. Bumke, and H. Chadwick, 1996: Air-sea exchange of water vapor and sensible heat: The Humidity Exchange Over the Sea (HEXOS) results. J. Geophys. Res., 101, 12 001-12 016.

Donelan, M. A., B. K. Haus, N. Reul, W. J. Plant, M. Stiassnie, H. C. Graber, O. B. Brown, and E. S. Saltzman, 2004: On the limiting aerodynamic roughness of the ocean in very strong winds. Geophys. Res. Lett., 31, L18306, doi:10.1029/ 2004GL019460.

Emanuel, K. A., 1995: Sensitivity of tropical cyclones to surface exchange coefficients and a revised steady-state model incorporating eye dynamics. J. Atmos. Sci., 52, 3969-3976.

_ 1999: Thermodynamic control of hurricane intensity. $\mathrm{Na}$ ture, 401, 665-669.

, 2003: A similarity hypothesis for air-sea exchange at extreme wind speeds. J. Atmos. Sci., 60, 1420-1428.

Falkovich, A., I. Ginis, and S. Lord, 2005: Ocean data assimilation and initialization procedure for the coupled GFDL/URI hurricane prediction system. J. Atmos. Oceanic Technol., 22, 1918-1932.

Ferrier, B. S., 2005: An efficient mixed-phase cloud and precipitation scheme for use in operational NWP models. Eos, Trans. Amer. Geophys. Union, 86 (Spring Meeting Suppl.), Abstract A42A-02.

_, Y. Jin, Y. Lin, T. Black, E. Rogers, and G. Dimego, 2002: Implementation of a new grid-scale cloud and precipitation scheme in the NCEP Eta model. Preprints, 15th Conf. on Numerical Weather Prediction, San Antonio, TX, Amer. Meteor. Soc., 280-283.

Franklin, J., 2006: Tropical cyclone report Hurricane Philippe. National Weather Service, National Hurricane Center, 10 pp. [Available online at http://www.nhc.noaa.gov/2005atlan.shtml.]

Ginis, I., 2002: Tropical cyclone-ocean interactions. AtmosphereOcean Interactions, W. Perrie, Ed., Advances in Fluid Mechanics Series, Vol. 33, WIT Press, 83-114.

_, W. Shen, and M. A. Bender, 1999: Performance evaluation of the GFDL coupled hurricane ocean prediction system in the Atlantic basin. Preprints, 23d Conf. on Hurricanes and Tropical Meteorology, Dallas, TX, Amer. Meteor. Soc., 607-610.

_ A. P. Khain, and E. Morozovsky, 2004: Effects of large eddies on the structure of the marine boundary layer under strong wind conditions. J. Atmos. Sci., 61, 3049-3064.

Global Climate and Weather Modeling Branch, 2003: The GFS atmospheric model. NCEP Office Note 442, 14 pp. [Available from NCEP, 5200 Auth Road, Washington, DC 20233.]

Grell, G. A., 1993: Prognostic evaluation of assumptions used by cumulus parameterizations. Mon. Wea. Rev., 121, 764-787.

Halkin, D., and T. Rossby, 1985: The structure and transport of the Gulf Stream at $73^{\circ}$ W. J. Phys. Oceanogr., 15, 1439-1452.

Hara, T., and S. E. Belcher, 2002: Wind forcing in the equilibrium range of wind-wave spectra. J. Fluid Mech., 470, 223-245.

$\longrightarrow$, and —, 2004: Wind profile and drag coefficient over mature ocean surface wave spectra. J. Phys. Oceanogr., 34, 2345-2358.

Holt, T., and S. Raman, 1988: A review and comparative evaluation of multilevel boundary layer parameterizations for firstorder and turbulent kinetic energy closure schemes. Rev. Geophys., 26, 761-780.

Hong, S.-Y., and H.-L. Pan, 1996: Nonlocal boundary layer vertical diffusion in a medium-range forecast model. Mon. Wea. Rev., 124, 2322-2339.

Horsfall, F., M. DeMaria, and J. M. Gross, 1997: Optimal use of large-scale boundary and initial fields for limited-area hurricane forecast models. Preprints, $22 d$ Conf. on Hurricanes and Tropical Meteorology, Fort Collins, CO, Amer. Meteor. Soc., 571-572.

Kimball, S. K., and F. C. Dougherty, 2006: The sensitivity of idealized hurricane structure and development to the distribution of vertical levels in MM5. Mon. Wea. Rev., 134, 1987-2008. 
Kurihara, Y., 1973: A scheme of moist convective adjustment. Mon. Wea. Rev., 101, 547-553.

— veloped in a three-dimensional numerical simulation model. J. Atmos. Sci., 31, 893-919.

— , and M. A. Bender, 1980: Use of a movable nested-mesh model for tracking a small vortex. Mon. Wea. Rev., 108, 17921809.

— C. L. Kerr, and M. A. Bender, 1989: An improved numerical scheme to treat the open lateral boundary of a regional model. Mon. Wea. Rev., 117, 2714-2722.

— M. A. Bender, R. E. Tuleya, and R. J. Ross, 1990: Prediction experiments of Hurricane Gloria (1985) using a multiply nested movable mesh model. Mon. Wea. Rev., 118, 21852198.

_, , and R. J. Ross, 1993: An initialization scheme of hurricane models by vortex specification. Mon. Wea. Rev., 121, 2030-2045.

,,-- R. E. Tuleya, and R. J. Ross, 1995: Improvements in the GFDL hurricane prediction system. Mon. Wea. Rev., 123, 2791-2801.

— R. E. Tuleya, and M. A. Bender, 1998: The GFDL hurricane prediction system and its performance in the 1995 hurricane season. Mon. Wea. Rev., 126, 1306-1322.

Large, W. G., and S. Pond, 1981: Open ocean momentum flux measurements in moderate to strong winds. J. Phys. Oceanogr., 11, 324-336.

Leaman, K. D., E. Johns, and T. Rossby, 1989: The average distribution of volume transport and potential vorticity with temperature at three sections across the Gulf Stream. J. Phys. Oceanogr., 19, 36-51.

Lozano, C. J., A. R. Robinson, H. G. Arango, A. Gangopadhyay, N. O. Sloan, P. J. Haley, and W. G. Leslie, 1996: An interdisciplinary ocean prediction system: Assimilation strategies and structured data models. Modern Approaches to Data Assimilation in Ocean Modelling, P. Malanotte-Rizzoli, Ed., Elsevier Oceanography Series, Vol. 61, Elsevier Science, 413-452.

Makin, V. K., 2005: A note on the drag of the sea surface at hurricane winds. Bound.-Layer Meteor., 115, 169-176.

Mellor, G. L., and T. Yamada, 1974: A hierarchy of turbulence closure models for planetary boundary layers. J. Atmos. Sci., 31, 1791-1806.

— , and —, 1982: Development of a turbulence closure model for geophysical fluid problems. Rev. Geophys. Space Phys., 20, 851-875.

Moon, I.-J., T. Hara, I. Ginis, S. E. Belcher, and H. Tolman, 2004a: Effect of surface waves on air-sea momentum exchange. Part I: Effect of mature and growing seas. J. Atmos. Sci., 61, 2321-2333.

_ - I. Ginis, and T. Hara, 2004b: Effect of surface waves on air-sea momentum exchange. Part II: Behavior of drag coefficient under tropical cyclones. J. Atmos. Sci., 61, 2334-2348.

$-, \ldots, \ldots$, and B. Thomas, 2007: A physics-based parameterization of air-sea momentum flux at high wind speeds and its impact on hurricane intensity predictions. Mon. Wea. Rev., 135, 2869-2878.

NAVOCEANO, cited 2006: GDEMV 3.0. [Available online at https://128.160.23.42/gdemv/gdem_desc_v30.html.]

Pan, H.-L., and W.-S. Wu, 1995: Implementing a mass flux convection parameterization package for the NMC mediumrange forecast model. NMC Office Note 409, 43 pp. [Available from NCEP, 5200 Auth Road, Washington, DC 20233.]
Powell, M. D., S. H. Houston, L. R. Amat, and N. MorisseauLeroy, 1998: The HRD real-time hurricane wind analysis system. J. Wind Eng. Ind. Aerodyn., 77-78, 53-64.

_ P. J. Vickery, and T. A. Reinhold, 2003: Reduced drag coefficient for high wind speeds in tropical cyclones. Nature, 422, 279-283.

Rennick, M. A., 1999: Performance of the Navy's tropical cyclone prediction model in the western North Pacific basin during 1996. Wea. Forecasting, 14, 297-305.

Robinson, A. R., and A. Gangopadhyay, 1997: Circulation and dynamics of the western North Atlantic. Part II: Dynamics of meanders and rings. J. Atmos. Oceanic Technol., 14, 13331351.

—, S. M. Glenn, M. A. Spall, L. J. Walstad, G. M. Gardner, and W. G. Leslie, 1989: Forecasting Gulf Stream meanders and rings. Eos, Trans. Amer. Geophys. Union, 70, 1464.

Sharan, M., and S. G. Gopalkrishnan, 1997: Comparative evaluation of eddy exchange coefficients for strong and weak wind stable boundary layer modeling. J. Appl. Meteor., 36, 545-559.

Surgi, N., S. Gopalkrishnan, Q. Liu, R. Tuleya, and W. O'Connor, 2006: The Hurricane WRF (HWRF): Addressing our nation's next generation hurricane forecast problems. Preprints, 27th Conf. on Hurricanes and Tropical Meteorology, Monterey, CA, Amer. Meteor. Soc., CD-ROM, 7A2.

Teague, W. J., M. J. Carron, and P. J. Hogan, 1990: A comparison between the Generalized Digital Environmental Model and Levitus climatologies. J. Geophys. Res., 95, 7167-7183.

Tolman, H. L., 2002: Validation of WAVEWATCH III version 1.15 for a global domain. NOAA/NWS/NCEP/OMB Tech. Note 213, 33 pp.

Troen, I., and L. Mahrt, 1986: A simple model of the atmospheric boundary layer: Sensitivity to surface evaporation. Bound.Layer Meteor., 37, 129-148.

Tuleya, R. E., 1988: A numerical study of the genesis of tropical storms observed during the FGGE year. Mon. Wea. Rev., 116, 1188-1208.

- 1994: Tropical storm development and decay: Sensitivity to surface boundary conditions. Mon. Wea. Rev., 122, 291-304.

_ , and Y. Kurihara, 1981: A numerical study on the effects of environmental flow on tropical storm genesis. Mon. Wea. Rev., 109, 2487-2506.

— and _ 1982: A note on the sea surface temperature sensitivity of a numerical model of tropical storm genesis. Mon. Wea. Rev., 110, 2063-2069.

_, M. A. Bender, and Y. Kurihara, 1984: A simulation study of the landfall of tropical cyclones. Mon. Wea. Rev., 112, 124-136.

Wu, C.-C., and K. A. Emanuel, 1994: On hurricane outflow structure. J. Atmos. Sci., 51, 1995-2003.

Wu, J., 1982: Wind-stress coefficients over sea surface from breeze to hurricane. J. Geophys. Res., 87, 9704-9706.

Yablonsky, R. M., and I. Ginis, 2008: Improving the initialization of coupled hurricane-ocean models by assimilating mesoscale oceanic features. Mon. Wea. Rev., in press.

Zeng, X., M. Zhao, and R. E. Dickinson, 1998: Intercomparison of bulk aerodynamic algorithms for the computation of sea surface fluxes using TOGA COARE and TAO data. J. Climate, 11, 2628-2644. 